\title{
Mesoscale Eddies Affect Near-Surface Turbulent Exchange: Evidence from Lidar and Tower Measurements
}

\author{
FABIAN EDER \\ Institute of Meteorology and Climate Research-Atmospheric Environmental Research (IMK-IFU), \\ Karlsruhe Institute of Technology, Garmisch-Partenkirchen, and Institute of Geography and \\ Geoecology (IfGG), Karlsruhe Institute of Technology, Karlsruhe, Germany \\ MARIUS SCHMIDT \\ Agrosphere (IBG-3), Jülich Research Centre, Jülich, Germany \\ THOMAS DAMIAN AND KATJA TRÄUMNER \\ Institute of Meteorology and Climate Research-Troposphere Research (IMK-TRO), Karlsruhe \\ Institute of Technology, Eggenstein-Leopoldshafen, Germany \\ MATTHIAS MAUDER \\ Institute of Meteorology and Climate Research-Atmospheric Environmental Research (IMK-IFU), \\ Karlsruhe Institute of Technology, Garmisch-Partenkirchen, and Institute of Geography and \\ Geoecology (IfGG), Karlsruhe Institute of Technology, Karlsruhe, Germany
}

(Manuscript received 6 June 2014, in final form 9 October 2014)

\begin{abstract}
The eddy-covariance technique tends to underestimate turbulent heat fluxes, which results in nonclosure of the surface energy balance. This study shows experimental evidence that mesoscale turbulent organized structures, which are inherently not captured by the standard eddy-covariance technique, can affect nearsurface turbulent exchange. By using a combined setup of three Doppler wind lidars above a croplanddominated area in Germany, low-frequency turbulent structures were detected in the surface layer down to a few meters above ground. In addition, data from two micrometeorological stations in the study area were analyzed with respect to energy balance closure. In accordance with several previous studies, the data confirm a strong friction velocity dependence of the energy balance residual. At both stations, the energy balance residual was found to be positively correlated with the vertical moisture gradient in the lower atmospheric boundary layer, but at only one station was it correlated with the temperature gradient. This result indicates that mesoscale transport probably contributes more to the latent heat flux than to the sensible heat flux, but this conclusion depends largely on the measurement site. Moreover, flow distortion due to tower mountings and measurement devices affects the energy balance closure considerably for certain wind directions.
\end{abstract}

\section{Introduction}

The eddy-covariance (EC) method (Swinbank 1951) is the most direct measurement technique for quantifying the ecosystem-atmosphere exchange of energy and

Corresponding author address: Fabian Eder, Institute of Meteorology and Climate Research-Atmospheric Environmental Research, Karlsruhe Institute of Technology, Kreuzeckbahnstraße 19, 82467 Garmisch-Partenkirchen, Germany.

E-mail: fabian.eder@kit.edu matter on a long-term basis. For this reason, large EC measurement networks have been established (Baldocchi et al. 2001). During the last few decades it became obvious that the EC technique usually does not close the energy balance at the surface-a fact that is known as the energy balance closure problem (Desjardins 1985; Lee and Black 1993; Twine et al. 2000; Wilson et al. 2002; Oncley et al. 2007; Foken 2008b; Hendricks-Franssen et al. 2010; Stoy et al. 2013). The available energy for turbulent transport, which is equal to the net radiation flux $-Q_{S}^{*}$ minus the ground heat flux at the surface $Q_{G}$, is 
not totally balanced by the sum of the sensible heat flux $Q_{H}$ and the latent heat flux $Q_{E}$ :

$$
-Q_{S}^{*}-Q_{G}=Q_{H}+Q_{E}+Q_{R}
$$

The energy balance residual $Q_{R}$ can amount to more than $100 \mathrm{~W} \mathrm{~m}^{-2}$, depending on measurement site, time of day, and time of year. As an alternative to Eq. (1), Wilson et al. (2002) defined the energy balance ratio $R$ as the sum of the turbulent fluxes divided by the available energy:

$$
R=\frac{Q_{H}+Q_{E}}{-Q_{S}^{*}-Q_{G}} .
$$

Given that general systematic errors of that extent in the measurement of $Q_{S}^{*}$ (Kohsiek et al. 2007) and $Q_{G}$ (Liebethal et al. 2005; Foken 2008b) can be excluded, the energy balance is not closed because the EC method underestimates $Q_{H}$ and $Q_{E}$.

Several reasons for the underestimation of turbulent heat fluxes are discussed in the literature. Early studies considered instrumental errors (Laubach et al. 1994; Goulden et al. 1996). Angle-of-attack-dependent errors of nonorthogonal sonic anemometers resulting from flow distortion were recently addressed (Kochendorfer et al. 2012; Nakai and Shimoyama 2012; Mauder 2013; Frank et al. 2013). In addition, the EC technique is based on assumptions of horizontal homogeneity and stationarity that are usually not completely fulfilled under typical field conditions. Therefore, rigorous data screening using a statistical test procedure is a necessary requirement for studying the surface energy balance (Mauder and Foken 2006; Mauder et al. 2013). Moreover, surface heterogeneities within the flux footprint of the measurement (Schmid 1997; Panin et al. 1998) as well as different source areas of the instruments (Culf et al. 2004; Göckede et al. 2008) have to be considered. The above-mentioned issues often cannot sufficiently explain why the turbulent fluxes are generally underestimated at many sites, however. A considerable amount of energy can be stored in the layer between the surface and the location of the measurement devices - for example, in the soil (Heusinkveld et al. 2004; Liebethal et al. 2005) and the plant biomass (Meyers and Hollinger 2004; Lindroth et al. 2010; Kilinc et al. 2012; Emmel et al. 2013). A small amount of energy is also fixed by photosynthesis (Blanken et al. 1997; Schmid et al. 2000; Meyers and Hollinger 2004). Accounting for all storage terms reduces $Q_{R}$ significantly, but it is not sufficient for closing the energy balance (Leuning et al. 2012; Stoy et al. 2013).

Another theory is that a considerable amount of $Q_{R}$ can be attributed to transport by turbulent structures that are inherently not captured by an EC tower (Mauder et al. 2007; Foken et al. 2011). These could be either low-frequency motions with time scales that are larger than the averaging time of the EC system (Sakai et al. 2001; Finnigan et al. 2003) or heterogeneity-induced secondary circulations that do not move with the mean wind (Lee and Black 1993; Mahrt 1998; Foken 2008b). These structures induce site-specific horizontal and vertical advection (Staebler and Fitzjarrald 2004; Higgins et al. 2013), which are difficult to capture with tower measurements (Aubinet et al. 2010). In this study, we focus on lowfrequency organized structures that fill the entire atmospheric boundary layer (ABL), and, following Kanda et al. (2004), we will call them "turbulent organized structures" (TOS). Large-eddy simulation (LES) studies showed that point measurements, such as the tower-based EC technique, are not able to capture TOS appropriately (Kanda et al. 2004; Inagaki et al. 2006; Steinfeld et al. 2007). Because of the limited grid resolution of current LES model runs, it is still not clear whether these structures reach down into the Prandtl layer or surface layer where flux measurements are usually conducted.

The objective of this study is to show that the TOS extend down to the ground and affect the near-surface exchange. First, the surface energy balances at two EC stations in an agricultural area in the west of Germany are determined. To demonstrate the existence of TOS in the Prandtl layer, data from three synchronously scanning Doppler lidars are analyzed. Because the flux contributions of the TOS cannot be measured directly, we evaluated their role for the vertical exchange of energy indirectly by analyzing the vertical gradients of temperature and moisture in the lower ABL. We assume that TOS are an effective exchange mechanism between the surface layer and the layers farther up in the atmosphere. They can only contribute substantially to the vertical fluxes if there is a pronounced difference in potential temperature and specific moisture between the different layers. During daytime conditions, the air close to the ground is usually warmer and wetter than above, and turbulent fluxes carried by TOS are consequently always positive. In accord with this situation, the neglect of the TOS transport by the EC method results in a systematic underestimation of turbulent heat fluxes, that is, the nonclosure of the surface energy balance. The vertical gradients in the lower ABL were detected with a radiometer and alternatively calculated from surface-layer universal functions. From these data, we attempt to identify parameters that are related to the different magnitudes of nonclosure of the energy balance observed at the sites.

\section{Measurements and methods}

\section{a. Site description}

The measurements were conducted in the Eifel/ Lower Rhine Valley Observatory of the Terrestrial 
Environmental Observatories (TERENO) network, which is located near Jülich in the west of Germany, close to the borders of Belgium and the Netherlands. The TERENO program is a long-term interdisciplinary research program in Germany that aims to observe the impacts of global change on terrestrial ecosystems at the regional level (Zacharias et al. 2011). The data were collected in the framework of the High Definition Clouds and Precipitation for Advancing Climate Prediction $\left[\mathrm{HD}(\mathrm{CP})^{2}\right]$ project, during the $\mathrm{HD}(\mathrm{CP})^{2} \mathrm{Ob}$ servational Prototype Experiment (HOPE), which took place in the area in April and May of 2013.

Data from two permanently running EC towers at Selhausen $\left(50.87^{\circ} \mathrm{N}, 6.45^{\circ} \mathrm{E}\right.$; $\left.103 \mathrm{~m} \mathrm{MSL}\right)$ and Merzenhausen $\left(50.93^{\circ} \mathrm{N}, 6.30^{\circ} \mathrm{E}\right.$; $\left.93 \mathrm{~m} \mathrm{MSL}\right)$ were used, which are located in the catchment of the Rur river (Fig. 1a). Most of the land in the study area is used for agriculture, mainly sugar beet and winter cereal cultivation (Graf et al. 2010). The regional landscape was originally flat, but it has changed dramatically as a result of the intensive brown-coal surface mining that has occurred there. The replanted spoil heap "Sophienhöhe" (302 m MSL) is the highest topographic elevation in the area and is located approximately $7.5 \mathrm{~km}$ north of the EC station at Selhausen and $11 \mathrm{~km}$ east of Merzenhausen (Fig. 1a). The two open pit mines that are located $4 \mathrm{~km}$ northeast and $6.5 \mathrm{~km}$ west of Selhausen are the deepest points in the area.

\section{b. Micrometeorological tower measurements}

In April and May of 2013, winter wheat was grown on the fields instrumented with EC systems at Selhausen and Merzenhausen. At both sites, all components of the surface energy balance were measured directly: the turbulent fluxes of sensible and latent heat, the net radiation, and the ground heat flux [Eq. (1)].

Model CSAT-3 sonic anemometers (Campbell Scientific, Inc.) were used to measure the three-dimensional wind vector and the sonic temperature and model LI7500 open-path infrared gas analyzers (Li-Cor, Inc., Biosciences) to measure the absolute humidity at $2 \mathrm{~m}$. The measurement frequency was $20 \mathrm{~Hz}$, and turbulent fluxes of sensible and latent heat were calculated using the "TK3.1" software package (Mauder and Foken 2011). The postprocessing of the field data followed the strategy presented in Mauder et al. (2013) and included the following: a raw-data delay correction that is based on maximizing the initial cross correlations of vertical wind speed with temperature and water vapor concentration, a spike-removal algorithm that is based on median absolute deviation, a planar-fit coordinate rotation (Wilczak et al. 2001), and corrections for high-frequency spectral losses (Moore 1986), the difference between sonic temperature and air temperature (Schotanus et al. 1983), and density fluctuations (Webb et al. 1980). For postfield quality assurance and quality control (QA/QC), a three-class quality-flagging scheme following that of Mauder et al. (2013) was applied to the 30-min statistics and fluxes. In this study, only data of the highest quality (flag 0) were used, except for the calculation of mean daily energy balance ratios in section 3a, where data of moderate quality (flag 1 ) were also used.

The net radiation was measured with an NR01 fourcomponent net radiometer (Hukseflux Thermal Sensors B.V.) at Selhausen and with an NR Lite net radiometer (Kipp \& Zonen B.V.) at Merzenhausen. The data from the NR Lite were corrected on the basis of side-by-side measurements with an NR01 radiometer at the end of the HOPE campaign. The ground heat flux was determined from three soil heat flux plates (model HFP01SC; Hukseflux), of which one was buried at 3-cm depth and two were placed at 8-cm depth; three Campbell Scientific model TCAV soil temperature sensors at 1-, 5- and 2-6-cm depth; and two Campbell Scientific model CS616 soil moisture sensors at $2.5-\mathrm{cm}$ depth using a calorimetric approach (Liebethal et al. 2005).

\section{c. Doppler-lidar wind measurements and dual-Doppler technique}

In the area of the Selhausen site, we also measured the spatially resolved turbulent flow field using Doppler lidars. To measure profiles of the vertical wind component above the site, we operated a Doppler wind lidar (Streamline model; HaloPhotonics, Ltd.) approximately $500 \mathrm{~m}$ northeast of the micrometeorological tower (Fig. 1b). The Streamline lidar emits a pulsed laser light of $1.5-\mu \mathrm{m}$ wavelength at a pulse repetition frequency of $15 \mathrm{kHz}$. To reduce the random error of the velocity estimate, an ensemble average over 15000 pulses is calculated so that the effective measurement frequency is about $1 \mathrm{~Hz}$. The Streamline lidar achieves a spatial resolution of $18 \mathrm{~m}$. The data from the first five range gates and from range gates with signal-to-noise ratios $<-17 \mathrm{~dB}$ were not used. The random error, determined from the difference between lag 0 and lag 1 of the autocovariance function (Lenschow and Kristensen 1985; Frehlich 2001), is $<0.2 \mathrm{~m} \mathrm{~s}^{-1}$ for signal-to-noise ratios $>-17 \mathrm{~dB}$. The Streamline either pointed vertically upward into the atmosphere to measure profiles of the vertical wind component, or it performed range-height indicator (RHI) scans (Fig. 1b). During the RHI scan, the lidar permanently changed its elevation angle; that is, it moved from $2^{\circ}$ elevation to $30^{\circ}$ elevation at $2^{\circ}$ intervals, but held its azimuth angle at $357^{\circ}$.

In addition, two Doppler lidars (WindTracer model; Lockheed Martin Technologies, Inc.) were used as 

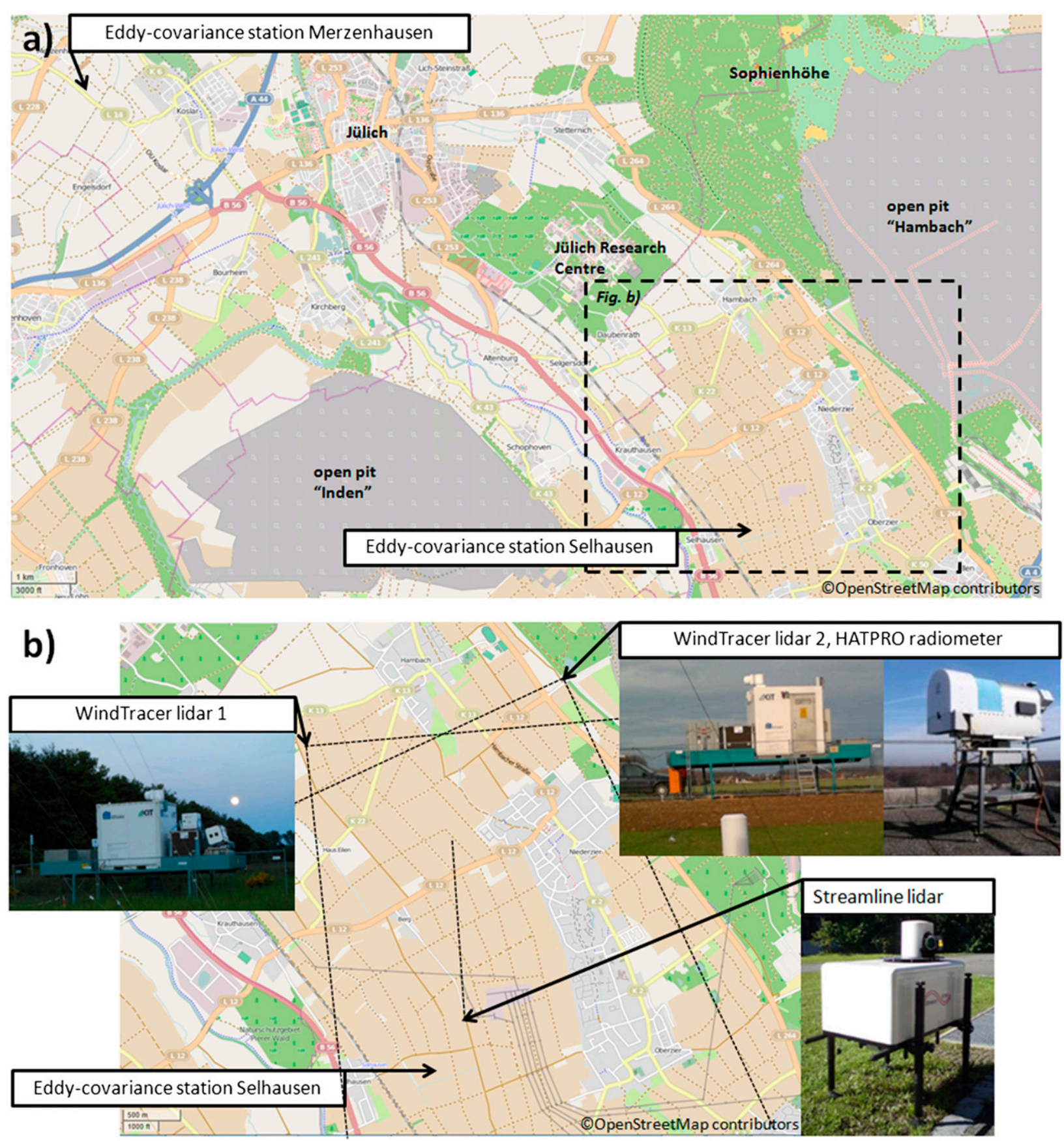

FIG. 1. (a) Overview map (http://openstreetmap.org; this map is made available under the Open Database License 1.0: http:// opendatacommons.org/licenses/odbl/1.0/) of the investigation area indicating the locations of the EC stations at Selhausen and Merzenhausen. (b) Instrument setup for Doppler wind lidar measurements in the Selhausen area: locations of the EC station at Selhausen, the Streamline Doppler lidar, and the WindTracer systems that were operated in dual-Doppler mode. The HATPRO radiometer for the temperature and moisture profiles was located next to the northeastern WindTracer system. The black dashed lines in (b) indicate the borders of the PPI scans of the WindTracer lidars and the orientation of the RHI scans performed by the Streamline lidar.

a coordinated dual-Doppler system that was located approximately $3.5 \mathrm{~km}$ north of the Selhausen site (Fig. 1b). Both lidars performed $90^{\circ}$-sector plan-position indicator (PPI) scans (Newsom et al. 2008) at a low elevation. The system placed in the northeast measured a sector PPI between the azimuth angles of $155^{\circ}$ and $245^{\circ}$, whereas the lidar placed in the northwest conducted measurements between the azimuth angles of $84^{\circ}$ and $174^{\circ}$. The 
elevation for both sector scans differed in a way $\left(0.025^{\circ}-\right.$ $\left.2.025^{\circ}\right)$ that the overlap area was tilted by $2^{\circ}$. In the overlap area of both measurements, the retrieval algorithm (Stawiarski 2014) that was used delivers a 2D horizontal wind field for an area of approximately $12 \mathrm{~km}^{2}$ with a spatial resolution of about $70 \mathrm{~m}$ and a temporal resolution of $12 \mathrm{~s}$. Both lidar systems were synchronized by a control program that ran at a remote operation station. Detailed information on instrumentation, error handling and scan optimization of the applied dual-Doppler technique can be found in Stawiarski et al. (2013). During HOPE, the dual-Doppler technique was also used to detect coherent structures with relatively short time scales in the surface layer (Träumner et al. 2014).

\section{d. Determination of vertical gradients}

Vertical profiles of potential temperature $\theta$ and specific humidity $q$ in the ABL were obtained from a passive microwave radiometer (HATPRO model; RPG Radiometer Physics $\mathrm{GmbH}$ ) that was located approximately $4 \mathrm{~km}$ northeast of the EC system at Selhausen (Fig. 1b). Average vertical profiles from 0 to $10000 \mathrm{~m}$ AGL were calculated every $15 \mathrm{~min}$. Here, we used the potential temperature and humidity measurements at 0 and $250 \mathrm{~m}$ to determine the differences between the surface layer and outer layer. The outer layer is the main part of the $\mathrm{ABL}$ above the surface layer. Additional information on instrument technique and measurement accuracy can be found in Rose et al. (2005), Löhnert et al. (2009), and Löhnert and Maier (2012).

If no profile measurements are available, the local vertical gradients of temperature $T$ and specific humidity $q$ can be calculated from surface-layer profile equations (Foken 2008a):

$$
\begin{aligned}
& \overline{w^{\prime} T^{\prime}}=-\frac{\alpha_{0} \kappa u_{*}}{\phi_{H}(z / L)} \frac{\partial T}{\partial \ln z} \text { and } \\
& \overline{w^{\prime} q^{\prime}}=-\frac{\alpha_{0 E} \kappa u_{*}}{\phi_{E}(z / L)} \frac{\partial q}{\partial \ln z},
\end{aligned}
$$

where $z$ is the aerodynamic measurement height. This approach was tested using the EC data from Selhausen and Merzenhausen. The turbulent fluxes of temperature $\overline{w^{\prime} T^{\prime}}$ and moisture $\overline{w^{\prime} q^{\prime}}$ and the friction velocity $u_{*}$ were measured using EC, the coefficients $\alpha_{0}$ and $\alpha_{0 E}$ are approximately equal to 1.25 , and the von Kármán constant $\kappa$ is taken to be 0.4. The universal functions of the exchange of temperature $\phi_{H}$ and moisture $\phi_{E}$ account for the dependence of the turbulent diffusion coefficient on the atmospheric stability parameter $z / L$, with $L$ being the Obukhov length. Thus, the vertical scalar profiles can be derived from

$$
\begin{aligned}
& T(z)-T\left(z_{0 T}\right)=\frac{\overline{w^{\prime} T^{\prime}}}{\alpha_{0} \kappa u_{*}}\left[\ln \frac{z}{z_{0 T}}-\psi_{H}\left(\frac{z}{L}\right)\right] \text { and } \\
& q(z)-q\left(z_{0 E}\right)=\frac{\overline{w^{\prime} q^{\prime}}}{\alpha_{0} \kappa u_{*}}\left[\ln \frac{z}{z_{0 E}}-\psi_{E}\left(\frac{z}{L}\right)\right],
\end{aligned}
$$

where $z_{0}$ is surface roughness length and $z_{0 T}$ and $z_{0 E}$ are roughness lengths of temperature and moisture (Foken 2008a). The value of $z_{0}$ was set to $0.01 \mathrm{~m}$, which has been suggested for short grass (Wiernga 1993) and should roughly equal the roughness length of winter wheat during spring, and we assumed that $z_{0 T}$ and $z_{0 E}$ were equal to $0.1 z_{0}$ (Foken 2008a). Here, we used the integral of the universal function for temperature after Businger et al. (1971) and as modified by Högström (1988):

$$
\begin{aligned}
& \psi_{H}\left(\frac{z}{L}\right)=2 \ln \left(\frac{1+y}{2}\right) \text { for } \frac{z}{L}<0 \\
& \psi_{H}\left(\frac{z}{L}\right)=-7.8 \frac{z}{L} \quad \text { for } \quad \frac{z}{L} \geq 0
\end{aligned}
$$

with

$$
y=0.95\left(1-11.6 \frac{z}{L}\right)^{1 / 2}
$$

We assumed that the integral of the universal function for the exchange of moisture $\psi_{E}$ is equal to $\psi_{H}$.

\section{e. Wavelet spectra}

Spectra of the horizontal and vertical wind components were calculated from high-frequency raw data measured by the sonic anemometer and the vertically pointing Streamline lidar. Time series with more than $5 \%$ of data missing as a result of unreliable measurements (sections $2 b, c)$ were excluded from the analysis. The remaining gaps in the time series were filled using linear interpolation. We did not apply any coordinate rotation to the measured wind vector. Then, the data from the sonic were block averaged to $1 \mathrm{~Hz}$ to reduce the computation time. The block-averaging procedure serves as a low-pass filter that removes all fluctuations with frequencies of greater than $1 \mathrm{~Hz}$, but we focus on low-frequency structures in this study.

The continuous wavelet transform was applied to the data using the Morlet mother wavelet with a frequency parameter of 6 (Torrence and Compo 1998; Mauder et al. 2007). The wavelet coefficients $W_{m}(a, b)$ were calculated from the convolution of a time series $m$ with the mother wavelet $\Psi$ shifted by $b$ and scaled by $a$. The squaring of the wavelet coefficients yields the wavelet scalogram, and the integration of the scalogram over $b$ yields the wavelet spectrum (Hudgins et al. 1993), 


$$
S_{m}(a)=\frac{\delta j}{a} \frac{\delta t}{C_{\delta}} \frac{1}{N} \sum_{b=0}^{N-1}\left|W_{m}(a, b)\right|^{2},
$$

where $\delta j=0.25$ is the spacing between the scales of the wavelet transform, $\delta t$ is the time step of the time series, and $C_{\delta}=0.776$ is a specific constant for the Morlet function (Torrence and Compo 1998). We considered only those wavelet coefficients outside of the "cone of influence" (Torrence and Compo 1998) so that edge effects are negligible. The integral over the total wavelet spectrum is equal to the variance of the time series, and integrating over parts of the spectrum gives the contributions of specific scales. Thus,

$$
r_{L}=\frac{\sum_{a>\tau} S_{m}(a)}{\sum S_{m}(a)}
$$

is the relative contribution of turbulent structures with time scales larger than $\tau$.

Analogous to Eq. (10), the wavelet cross spectrum of two time series $m$ and $n$ gives the spectral contributions to the turbulent flux $\overline{m^{\prime} n^{\prime}}$ and is defined as

$$
S_{m n}(a)=\frac{\delta j}{a} \frac{\delta t}{C_{\delta}} \frac{1}{N} \sum_{b=0}^{N-1} W_{m}(a, b) W_{n}^{*}(a, b),
$$

with $W_{m}(a, b)$ being the wavelet coefficients of time series $m$ and $W_{n}^{*}(a, b)$ being the complex conjugates of the wavelet coefficients of time series $n$ (Hudgins et al. 1993).

\section{Results}

\section{a. Observed energy balance closure}

First, the mean daily surface energy balance ratios at Merzenhausen and Selhausen were calculated from the net radiation and surface heat fluxes according to Eq. (2). We detected slightly higher energy balance ratios $(0.85 \pm$ 0.13 ) at the site in Selhausen and slightly lower values at the Merzenhausen site $(0.76 \pm 0.11)$. Both results were in good agreement with those from Schmidt et al. (2012), in which a mean closure of 0.8 was reported for an EC tower at a winter wheat field in Selhausen over a period of $2 \mathrm{yr}$. In the current study, we found considerable day-to-day variability at both sites.

Second, the 30-min energy balance ratios were calculated using the daytime measurements, and an effect of the mean wind direction on the energy balance closure was found (Figs. 2a,b): at both sites, lower energy balance ratios were measured for northeasterly and easterly winds than for westerly winds. This dependence on wind direction may be explained by heterogeneities on the landscape scale (Panin and Bernhofer 2008), nonhomogeneous fetch conditions (Panin et al. 1998; Foken 2008b), or flow distortion by the tower and the measurement devices (Högström and Smedman 2004; Nakai et al. 2006; Kochendorfer et al. 2012; Nakai and Shimoyama 2012). We exclude the first explanation, because the most prominent heterogeneity on the landscape scale, the Sophienhöhe hill, lies in different wind sectors for Selhausen (north) and Merzenhausen (east). In addition, the large surface-mining area west of Selhausen did not have any influence on the energy balance closure (Fig. 2a). The horizontal wind speed $u$ normalized by the friction velocity $u_{*}$ showed larger fluctuations in the northeastern and eastern wind sectors at both sites (Figs. 2c,d). This result might suggest the presence of roughness heterogeneities within the flux footprint, but the surface northeast and east of the towers is flat and homogeneous. The third potential explanation is that flow distortion by the tower mountings and measurement devices caused the poor energy balance closure and the differences in $u / u_{*}$ for the northeastern and eastern wind directions. This explanation is supported by the systematic, directiondependent fluctuations of the vertical wind component in that wind sector $\left(360^{\circ}-135^{\circ}\right.$; Figs. $\left.2 \mathrm{e}, \mathrm{f}\right)$. The standard QA/QC tests did not detect this flow-distortion problem, although we show in Fig. 2 only data with the best quality flag (section 2b). The exclusion of those days when winds came from the $360^{\circ}-135^{\circ}$ sector leads to slightly higher energy balance ratios ( 0.88 for Selhausen and 0.80 for Merzenhausen), but the energy balance is still far from being closed completely. Therefore, we investigate in the following sections whether TOS can help to explain the remaining lack of energy balance closure.

\section{b. TOS in the surface layer}

In this section, we show examples of TOS with time scales of larger than $30 \mathrm{~min}$ that extended down to the surface layer at the study site. For this purpose, we used 30-min averages of dual-Doppler lidar data to visualize the horizontal dimensions of the TOS. In addition, the Streamline Doppler wind lidar data gave information about the vertical extent of these structures. First, we focus on two days with high net radiation, different wind regimes, and different energy balance ratios (Fig. 3). The date 7 April represents a day with low wind speeds $(u=$ $\left.0-2 \mathrm{~m} \mathrm{~s}^{-1}\right)$ and a relatively low energy balance ratio $(0.79$ at Selhausen and 0.70 at Merzenhausen), whereas on 16 April higher wind speeds prevailed $\left(u=2-4 \mathrm{~m} \mathrm{~s}^{-1}\right)$ and the energy balance ratio was higher ( 0.97 at Selhausen and 0.85 at Merzenhausen). The relatively large residuals in the morning hours are most probably due to 

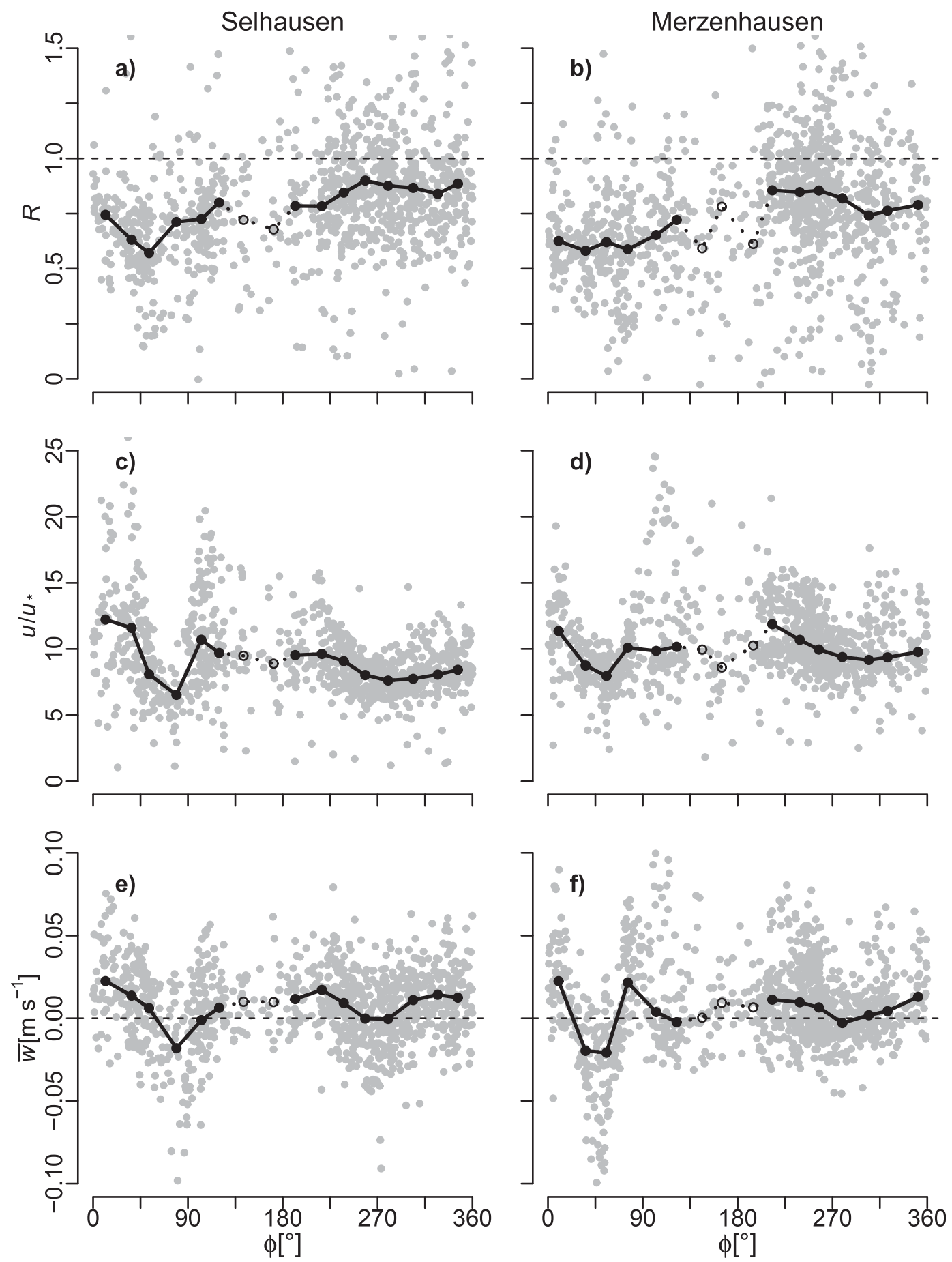

FIG. 2. Dependence of (a),(b) the energy balance ratio $R$, (c),(d) the horizontal wind speed normalized by friction velocity $u / u_{*}$, and (e),(f) the mean vertical wind speed $\bar{w}$ after planar-fit rotation on wind direction $\phi$ at Selhausen and Merzenhausen. The gray points show all 30-min data with the best quality flag that were measured during daytime $\left(-Q_{S}-Q_{G}>20 \mathrm{~W} \mathrm{~m}^{-2}\right)$. The filled black circles and solid lines show the mean values of wind sectors (width of $22.5^{\circ}$ ) with at least 30 data points, and the open circles and dotted lines show the mean of the wind sectors with less than 30 data points. 

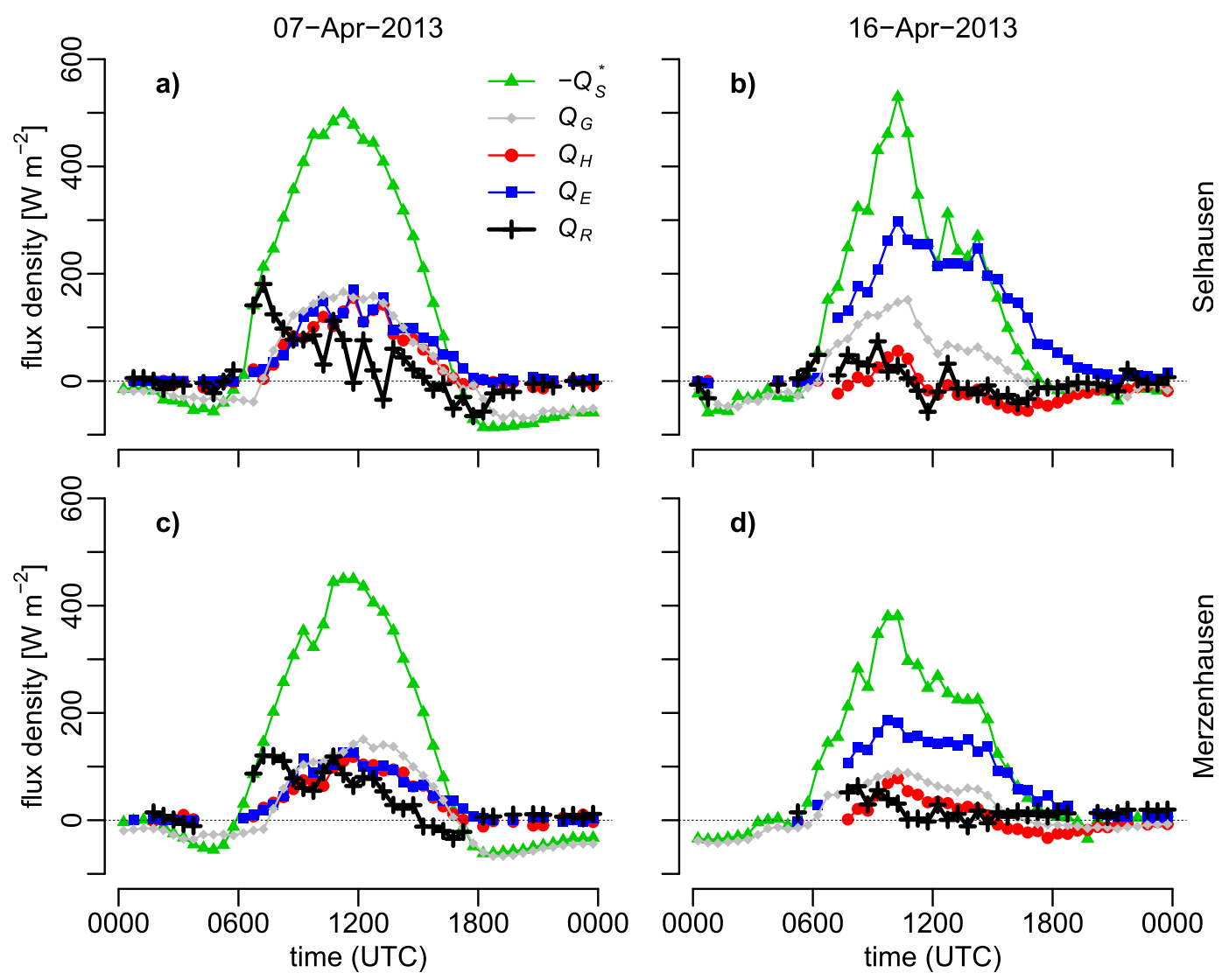

FIG. 3. Net radiation $Q_{S}$, ground heat flux $Q_{G}$, sensible heat flux $Q_{H}$, latent heat flux $Q_{E}$, and residual $Q_{R}$ on (a),(c) 7 and (b),(d) 16 Apr 2013, measured at (top) Selhausen and (bottom) Merzenhausen.

the energy storage in the biomass of the winter wheat (Leuning et al.2012) and the energy that is used to melt the white frost on the surface, for which we did not account.

On both days, we detected TOS in the surface layer. On 7 April (i.e., the low-wind case), cellular structures were identified in the dual-Doppler data around noontime (Fig. 4a) and in the early afternoon. The example in Fig. 4a shows convergence $-\nabla(u v)$ in the horizontal wind field close to the vertically pointing Streamline lidar. It was calculated from the $2 \mathrm{D}$ horizontal wind field $(u, v)$ :

$$
-\nabla(u v)=-\left(\frac{d u}{d x}+\frac{d v}{d y}\right)
$$

where $u$ is the zonal wind component, $v$ is the meridional wind component, $x$ is the zonal direction, and $y$ is the meridional direction.

This convergence zone in the surface layer was associated with a quasi-permanent net vertical updraft that extended through the whole ABL for most of the period (Figs. 4b,c). In the case of high background wind (i.e., on 16 April), we did not find cellular structures but we detected parallel bands of higher wind speeds with low-wind bands between them (Fig. 5a). In the vertically pointing lidar, we detected structures with short time scales (Fig. 5b) and a small mean vertical wind component (Fig. 5c). In the entire dual-Doppler dataset, we found clear cellular structures only on 7 April. In the 30-min-averaged horizontal wind fields, we usually found bands of different wind speeds that are aligned parallel to the mean wind direction. This could be surfacelayer streaks (Cantwell 1981; Robinson 1991; Moeng and Sullivan 1994), but streaks are high-frequency structures with spatial dimensions of several hundreds of meters (Newsom et al. 2008; Träumner et al. 2014) that should vanish when calculating a 30-min average. Therefore, we argue that we detected traces of large TOS that probably fill in the whole ABL and reach down into the surface layer because their spanwise extent is on the order of the boundary layer depth and their longitudinal extent is larger than the dual-Doppler lidar's field of view.

To investigate how deep the TOS can penetrate into the surface layer, we performed additional RHI scans with the Streamline wind lidar. An RHI scan describes a series of measurements at different elevation angles and constant azimuth angle. For example, the data from 


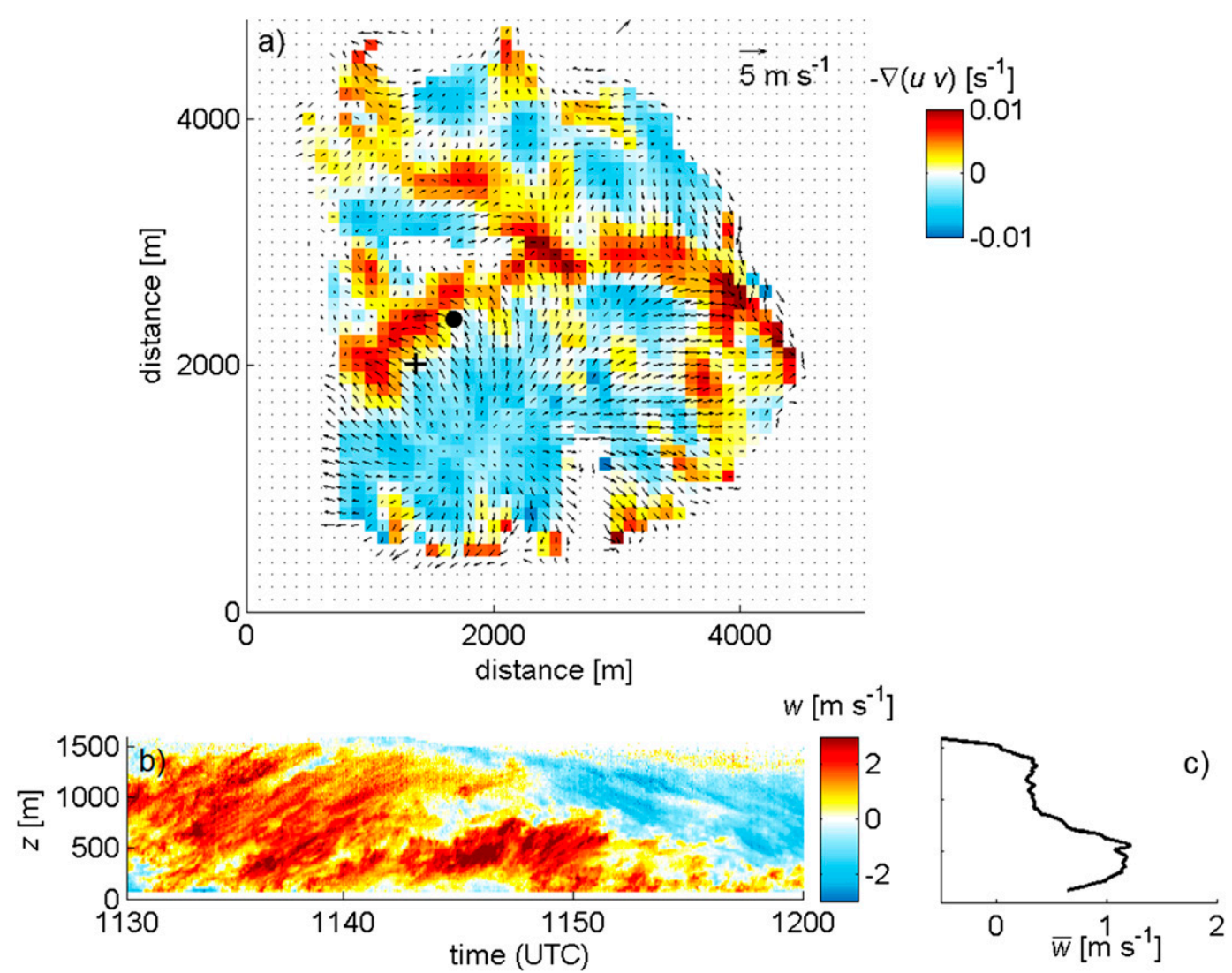

FIG. 4. (a) The 30-min average (1130-1200 UTC 7 Apr 2013) of the horizontal flow field around Selhausen measured with the dual-Doppler technique, located on a slightly tilted overlap area at 20-120 m AGL. The arrows show the horizontal wind vector, the colors show convergences and divergences in the flow field, the black dot indicates the location of the Streamline lidar, and the black plus sign shows the location of the EC station at Selhausen. (b) The vertical wind component $w$ measured with the Streamline wind lidar during the 30-min period.

(c) The vertical profile of the 30-min average of $w$ measured with the Streamline lidar.

1030 to $1100 \mathrm{UTC} 17$ April $\left(u \approx 1 \mathrm{~m} \mathrm{~s}^{-1}\right)$ show a mixture of cell-like structures and parallel bands in the horizontal wind field with convergence at a distance of 1000 $1500 \mathrm{~m}$ from the Streamline lidar and divergence at a distance of 300-1000 $\mathrm{m}$ in the direction of the RHI scan (Fig. 6a). In the RHI scan we found that at the same time and at the same distances from the lidar the radial velocities changed their sign, which indicates convergence and divergence. These convergence and divergence zones reached down to the lowest measurement points above the ground ( $\sim 15 \mathrm{~m} \mathrm{AGL})$. On 28 April, we found even stronger convergence in the RHI scans (Fig. 6c), but no dual-Doppler data were available for that time period. Thus, we reason that TOS that fill the entire ABL can penetrate deep into the Prandtl layer (Figs. 6b,c).

Since TOS can reach close to the surface, they should also affect the data of the micrometeorological tower. To prove that, we calculated wavelet spectra from the daily time series of the $u$ and $w$ components measured with the sonic anemometer at the Selhausen site (Fig. 7).
In addition, we determined the $w$ spectra in the outer layer using the data from the vertically pointing Streamline wind lidar. The $w$ spectra in the surface layer show some low-frequency contribution $(f<1 / 1800 \mathrm{~Hz})$ on 7 April that is due to the convective coherent structures but not on 16 April, and the overall low-frequency contribution to the surface-layer $w$ spectra is weak. The outer-layer $(z \geq 100 \mathrm{~m}) w$ spectra and surface-layer $u$ spectra show a significant low-frequency part, and they have similar spectral shapes. This result suggests that the TOS measured with the dual-Doppler technique (Figs. 4, 5a, and 6a) affect the horizontal wind component in the surface layer and consequently can cause horizontal advection and horizontal flux divergences that are not considered in the standard EC approach (Finnigan et al. 2003).

Another interesting feature is that on 7 April the surface-layer $u$ spectrum and the outer-layer $w$ spectra were shifted to lower frequencies, which could explain the poorer energy balance closure on that day. For this 


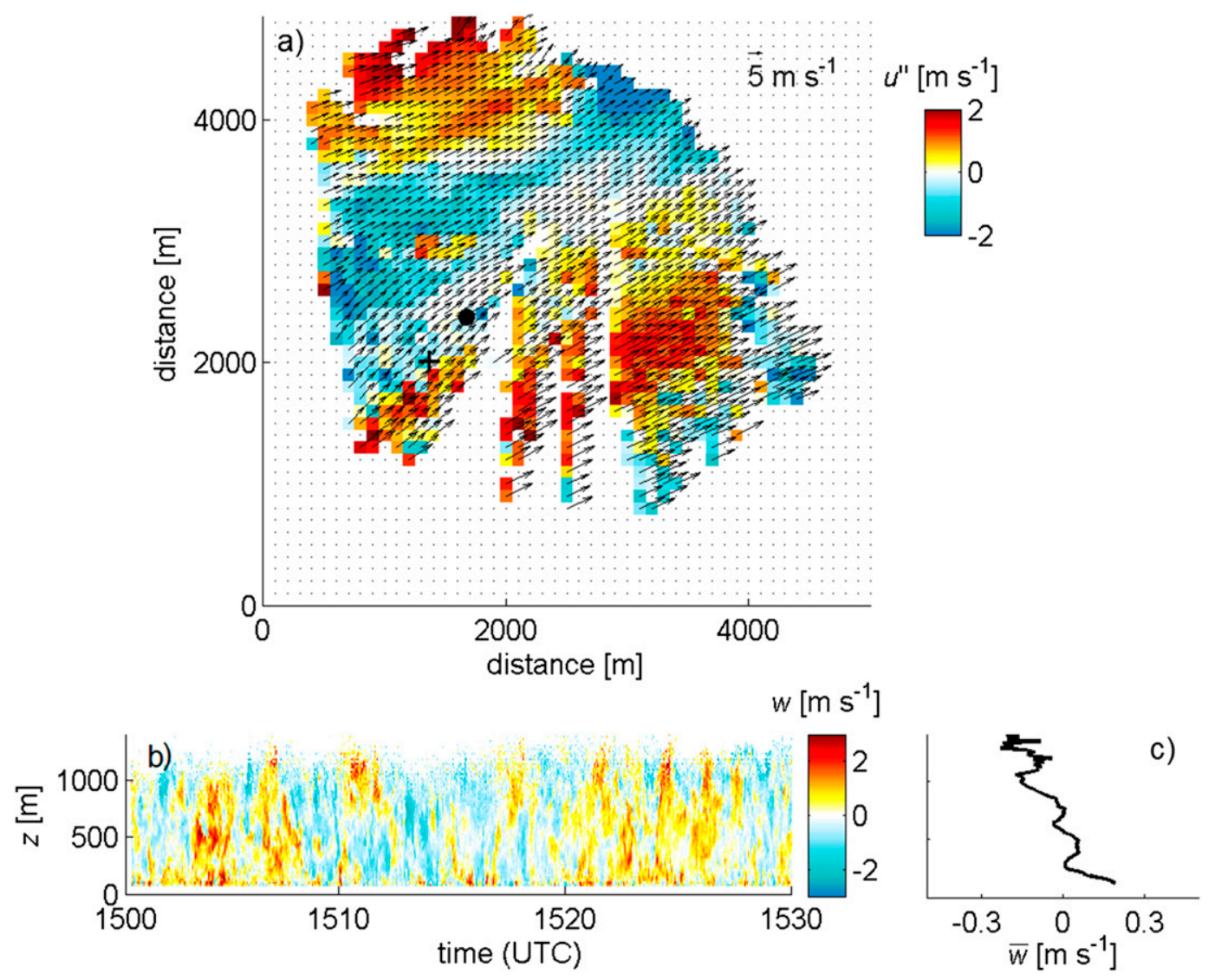

FIG. 5. The horizontal flow field and vertical wind component around Selhausen at 1500-1530 UTC 7 Apr 2013. This layout is identical to that in Fig. 4 except for the color scale in (a), which now indicates the spatial deviations $u^{\prime \prime}$ from the space-time-averaged horizontal wind speed.

reason, we calculated the relative low-frequency contribution to the daily $u$ spectra using Eq. (11). We did not find an appreciable correlation between the low-frequency part of the $u$ spectrum and the energy balance ratio (linear model; coefficient of determination $R^{2}=0.05$ ), which suggests that considering the strengths of TOS alone is not sufficient for explaining the unclosed energy balance. In addition, the vertical scalar gradients need to be taken into account, which is done in the following section.

\section{c. Relation of friction velocity and vertical gradients to the energy balance residual}

As explained in section 1, a considerable vertical gradient in temperature and/or humidity is necessary in order that TOS can contribute to the near-surface energy exchange. In other words, the magnitude of the energy balance residual should correlate with the vertical gradient of temperature and humidity in the lower part of the ABL. For this purpose, we determined the temperature and moisture difference between the surface layer and a height of $250 \mathrm{~m}$ AGL using the profiles from the
HATPRO microwave radiometer. Then, we performed a linear-regression analysis between the mean daily energy balance residual and the corresponding mean vertical gradients, by considering only the daytime values $(0800$ 1700 UTC). We excluded days on which the mean wind direction was within the $360^{\circ}-135^{\circ}$ sector (section $3 a$ ). In a second step, we also excluded days with less than $50 \%$ data availability, mainly as a result of rain events and poor data quality according to the applied QA/QC scheme (section 2b).

The regression analysis between various atmospheric parameters and the mean daily energy balance residual at the Selhausen site revealed a negative correlation between $Q_{R}$ and the friction velocity measured with the sonic anemometer (Fig. 8a), with $R^{2}=0.23$. With respect to the vertical gradients, there was no correlation with temperature (Fig. 8b) but there was a correlation with atmospheric moisture (Fig. 8c), with $R^{2}=0.36$. This result means that large energy balance residuals predominantly occurred during periods with large vertical moisture differences in the lower ABL. The coefficients of determination become even larger $\left(R^{2}=0.32\right.$ for 

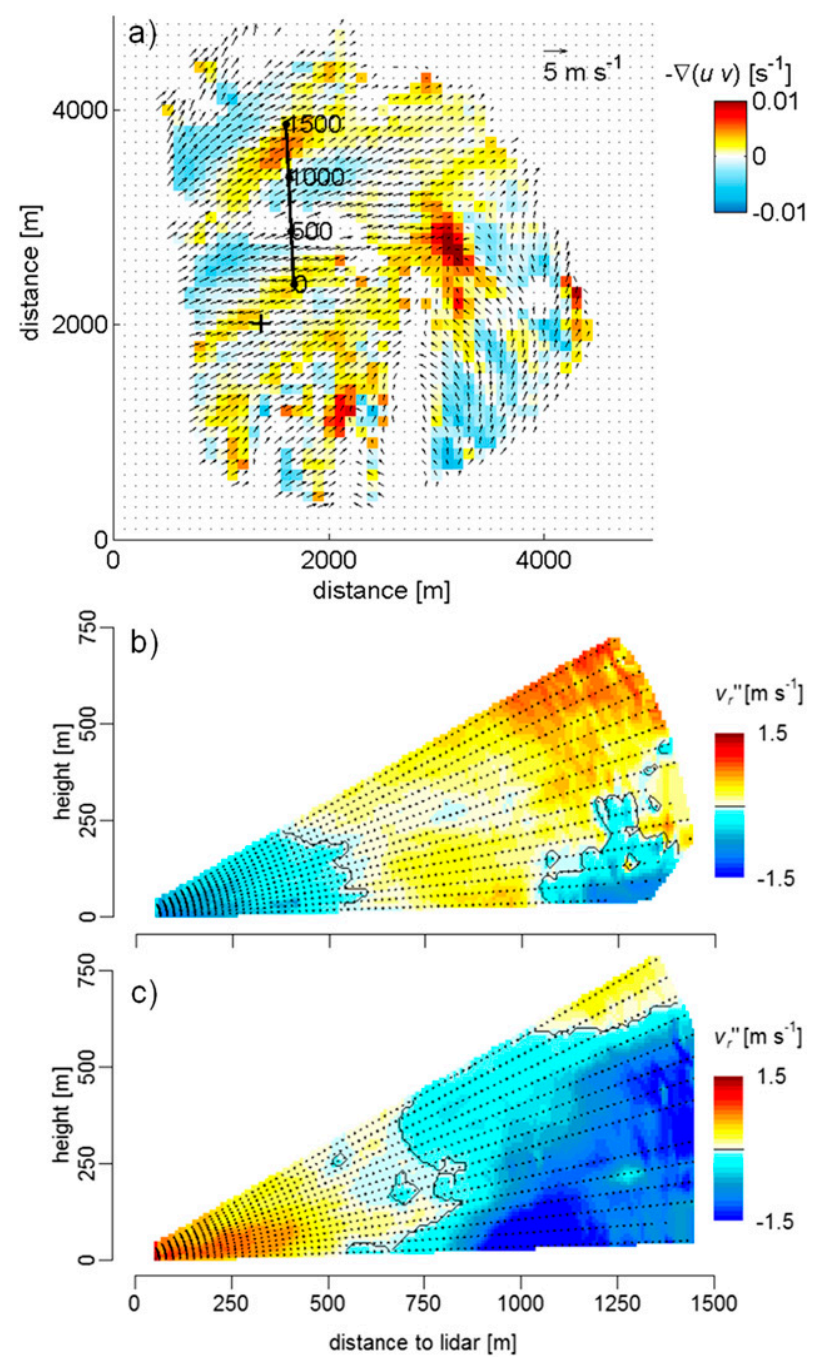

FIG. 6. (a) The 30-min average (1030-1100 UTC 17 Apr 2013) of the horizontal flow field around Selhausen (layout similar to that in Fig. 4a); the solid black line shows the orientation of the RHI scan of the Streamline lidar. (b) The synchronous 30-min average of the radial velocity deviation from space-time-averaged wind $v_{r}^{\prime \prime}$, measured with the Streamline lidar that performed RHI scans between $0^{\circ}$ and $30^{\circ}$ elevation and at $357^{\circ}$ azimuth angle. (c) The 30-min average of $v_{r}^{\prime \prime}$ at 1230-1300 UTC 28 Apr 2013.

$u_{*}$ and 0.50 for the moisture gradient) if we exclude the outlier in Figs. 8a-c (marked with a circle). The multiple linear regression of the energy balance residual against $u_{*}$ and the moisture gradient, that is,

$$
Q_{R}=c_{0}+c_{1} \frac{1}{u_{*}}+c_{2} \lambda \frac{\Delta q}{\Delta z},
$$

has an $R^{2}$ of 0.40 (all days) and 0.60 (without the outlier), with $c_{0}=-44.09 \mathrm{~W} \mathrm{~m}^{-2}, c_{1}=8.38 \mathrm{~kg} \mathrm{~m} \mathrm{~s}^{-4}$, and $c_{2}=$ $3.69 \mathrm{~kg} \mathrm{~m}^{-1} \mathrm{~s}^{-1}$ being regression coefficients (without the outlier) and $\lambda$ being the heat of vaporization.
As an alternative to the HATPRO profiles, we calculated the vertical gradients between the surface and the eddy-tower measurement height from the universal functions following Eqs. (5)-(9). Again, $Q_{R}$ correlates with the vertical moisture gradient $\left(R^{2}=0.33\right)$ but not with the vertical temperature gradient (Figs. 9a,b). The multivariate regression of $Q_{R}$ against $u_{*}$ and the moisture gradient yields an $R^{2}$ of 0.42 (all days) and 0.52 (without the outlier), with $c_{0}=-33.61 \mathrm{~W} \mathrm{~m}^{-2}, c_{1}=$ $11.75 \mathrm{~kg} \mathrm{~m} \mathrm{~s}^{-4}$, and $c_{2}=2.90 \times 10^{-3} \mathrm{~kg} \mathrm{~m}^{-1} \mathrm{~s}^{-1}$ (without the outlier).

When the regression analysis was repeated for the Merzenhausen site, only very weak correlations were found between the vertical scalar gradients determined from the HATPRO radiometer and the mean daytime $Q_{R}$ at Merzenhausen, with $R^{2}$ values of 0.13 for the temperature gradient and 0.03 for the moisture gradient (data not shown). The gradients determined from the radiometer were probably not representative for the Merzenhausen site because of the larger distance of approximately $12.5 \mathrm{~km}$ between the locations of the HATPRO device and the EC station (Fig. 1). We calculated the vertical gradients from the universal functions applied to the local tower measurement, and we found a correlation between $Q_{R}$ and the temperature $\left(R^{2}=0.35\right)$ as well as the moisture gradient $\left(R^{2}=0.38\right)$, whereas the correlation with $u_{*}$ is weak $\left(R^{2}=0.11\right.$; Fig. 10). The multiple linear model

$$
Q_{R}=c_{0}+c_{1} c_{p} \frac{\Delta T}{\Delta z}+c_{2} \lambda \frac{\Delta q}{\Delta z}
$$

has an $R^{2}$ value of 0.46 , with $c_{p}$ being the specific heat capacity of air at constant pressure and $c_{0}=$ $-3.63 \mathrm{~W} \mathrm{~m}^{-2}, c_{1}=11.45 \times 10^{-3} \mathrm{~kg} \mathrm{~m}^{-1} \mathrm{~s}^{-1}$, and $c_{2}=$ $5.26 \times 10^{-3} \mathrm{~kg} \mathrm{~m}^{-1} \mathrm{~s}^{-1}$. At the Merzenhausen site, the inclusion of $u_{*}$ does not improve the model performance significantly. In summary, the friction velocity, the temperature gradient, and the moisture gradient can help to explain large energy balance residuals on a daily basis, but not all three parameters were equally relevant for the two sites analyzed in this study.

\section{Discussion}

In this study, we tested the hypothesis that TOS are a major cause for the unclosed energy balance. On 7 April, the dual-Doppler data showed cellular structures (Fig. 4a), whereas we usually detected parallel bands with different wind speeds as, for example, on 16 April (Fig. 5a), in the horizontal wind field of the surface layer. The cellular structures indicate the presence of convective cells, or Bénard cells (Ahlers et al. 2009), which are a typical feature in LES studies of the buoyancy-driven 

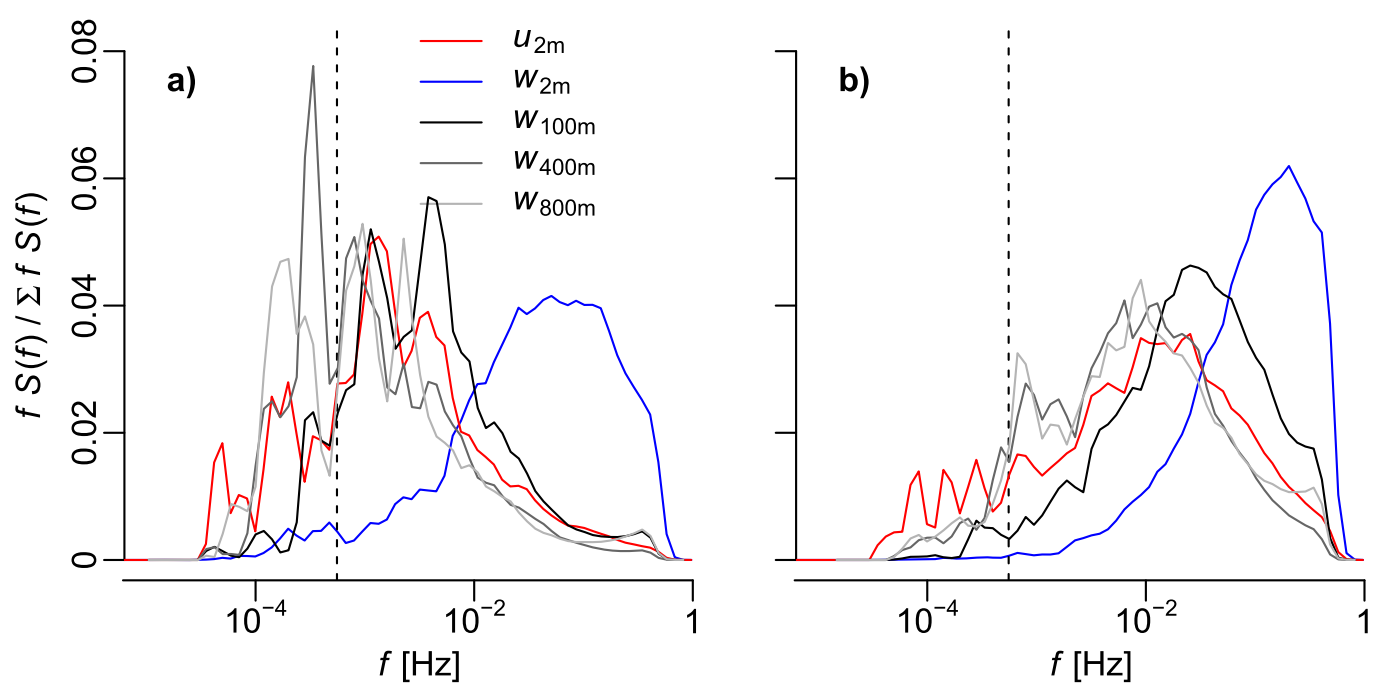

FIG. 7. Wavelet spectra of horizontal $(u)$ and vertical $(w)$ wind components measured at Selhausen on (a) 7 and (b) 16 Apr 2013. The measurements at $2 \mathrm{~m}$ AGL were conducted with a CSAT-3 sonic anemometer, and the measurements at 100,400 , and $800 \mathrm{~m}$ were taken with the Streamline Doppler wind lidar; the vertical dashed line indicates $f=1 / 1800 \mathrm{~Hz}$ (i.e., a period of $30 \mathrm{~min}$ ).

ABL (Schmidt and Schumann 1989; Kanda et al. 2004; Huang et al. 2008). Those convective cells have been described as "spoke patterns" (Schmidt and Schumann 1989); that is, they form a network of narrow convergence lines with strong updrafts aloft and wider circular downdraft regions. The data from the vertically pointing lidar indicate that the updraft regions are located above the convergence lines and that these updrafts reach far up into the atmosphere (Fig. 4b). According to LES studies, the surface-layer convective cells merge into large buoyancy-driven updrafts that fill the entire ABL (Schmidt and Schumann 1989; Moeng and Sullivan 1994). Such large-scale turbulent structures were suspected to be responsible for the saw-blade pattern of the energy balance residual (Blanken et al. 1997) that we observed at Selhausen on 7 April (Fig. 3a): if such large structures are
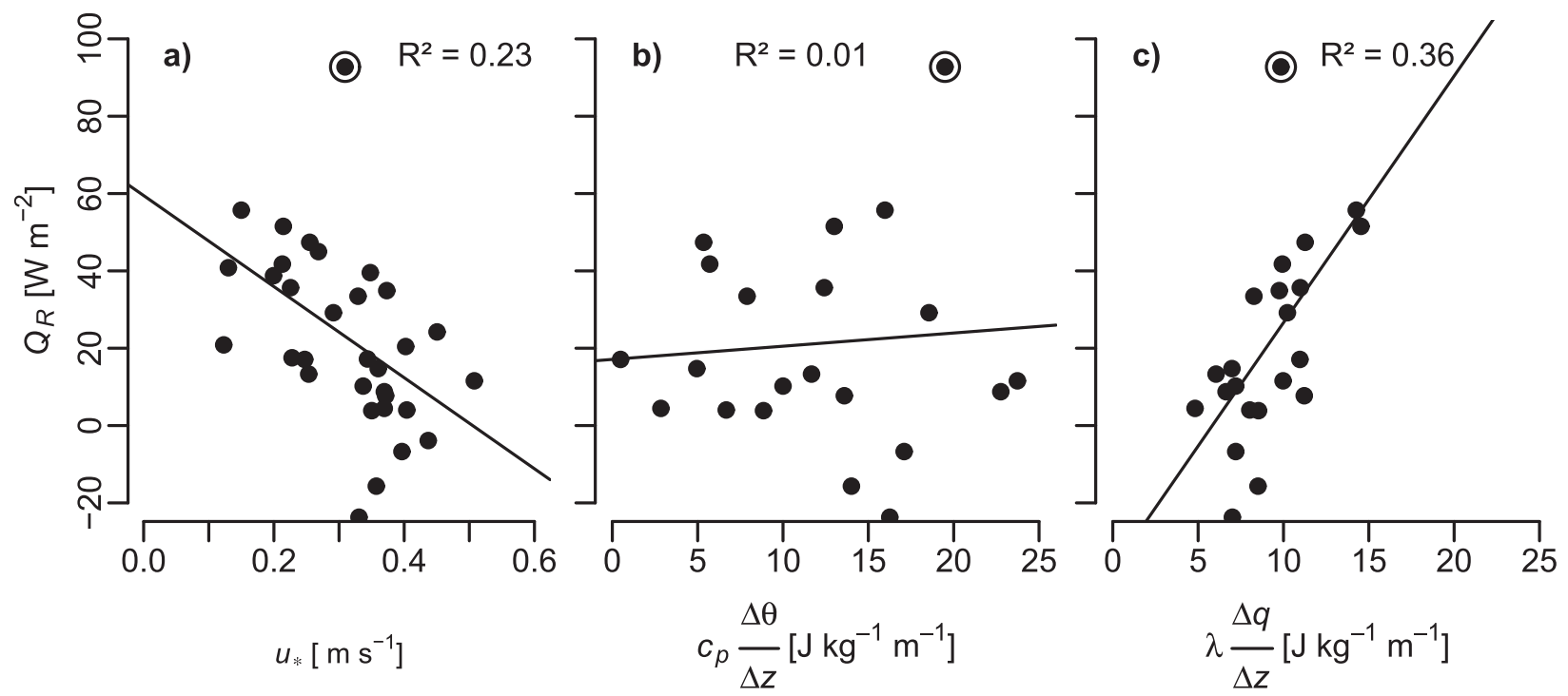

FIG. 8. Linear regression analysis between the daily averages of the energy balance residual $Q_{R}$ at Selhausen and (a) friction velocity $u_{*}$, (b) the vertical gradient of potential temperature $\Delta \theta / \Delta z$ multiplied by $c_{p}$, and (c) specific humidity $\Delta q / \Delta z$ multiplied by $\lambda$, determined from the HATPRO profiles (0-250 m AGL). Days with a mean wind direction from $0^{\circ}$ to $135^{\circ}$ and less than $50 \%$ data availability were excluded from the analysis. The specific heat capacity of air at constant pressure $c_{p}$ and the heat of vaporization $\lambda$ were needed to convert to energy units. For each data point, we used only the daytime data measured between 0800 and 1700 UTC. The circle denotes an outlier (see text). 

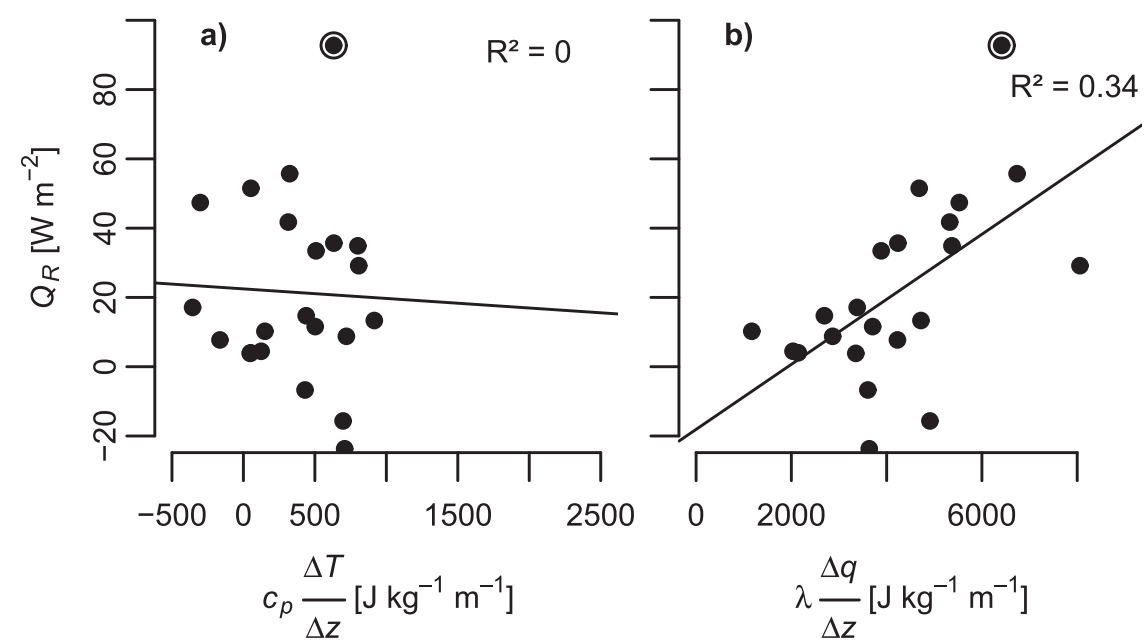

FIG. 9. Linear regression analysis between the daily averages of the energy balance residual $Q_{R}$ at Selhausen and (a) the vertical gradient of temperature $\Delta T / \Delta z$ multiplied by $c_{p}$ and (b) the specific humidity $\Delta q / \Delta z$ multiplied by $\lambda$, determined from the universal functions $(0-2 \mathrm{~m})$. Days with a mean wind direction from $0^{\circ}$ to $135^{\circ}$ and less than $50 \%$ data availability were excluded from the analysis. Only the daytime data measured between 0800 and 1700 UTC are used.

(are not) properly sampled by the EC measurement, that is, the cell does (does not) advect past the tower within the 30 -min averaging interval, the energy balance residual is smaller (larger). Pure convective cells were only detected with the dual-Doppler technique for several hours, however, when the mean wind speed was low enough and buoyancy was high. The horizontal wind field in the surface layer was usually dominated by parallel bands with different wind speeds (Figs. 5a and 6a) that could be traces of horizontal rolls (Etling and Brown 1993; Moeng and Sullivan 1994) or secondary circulations that are induced by upstream surface heterogeneities (Maronga and Raasch 2013). We found evidence that, if the background wind is high enough, there is strong mechanical mixing in the surface layer and the majority of the energy-transporting eddies are

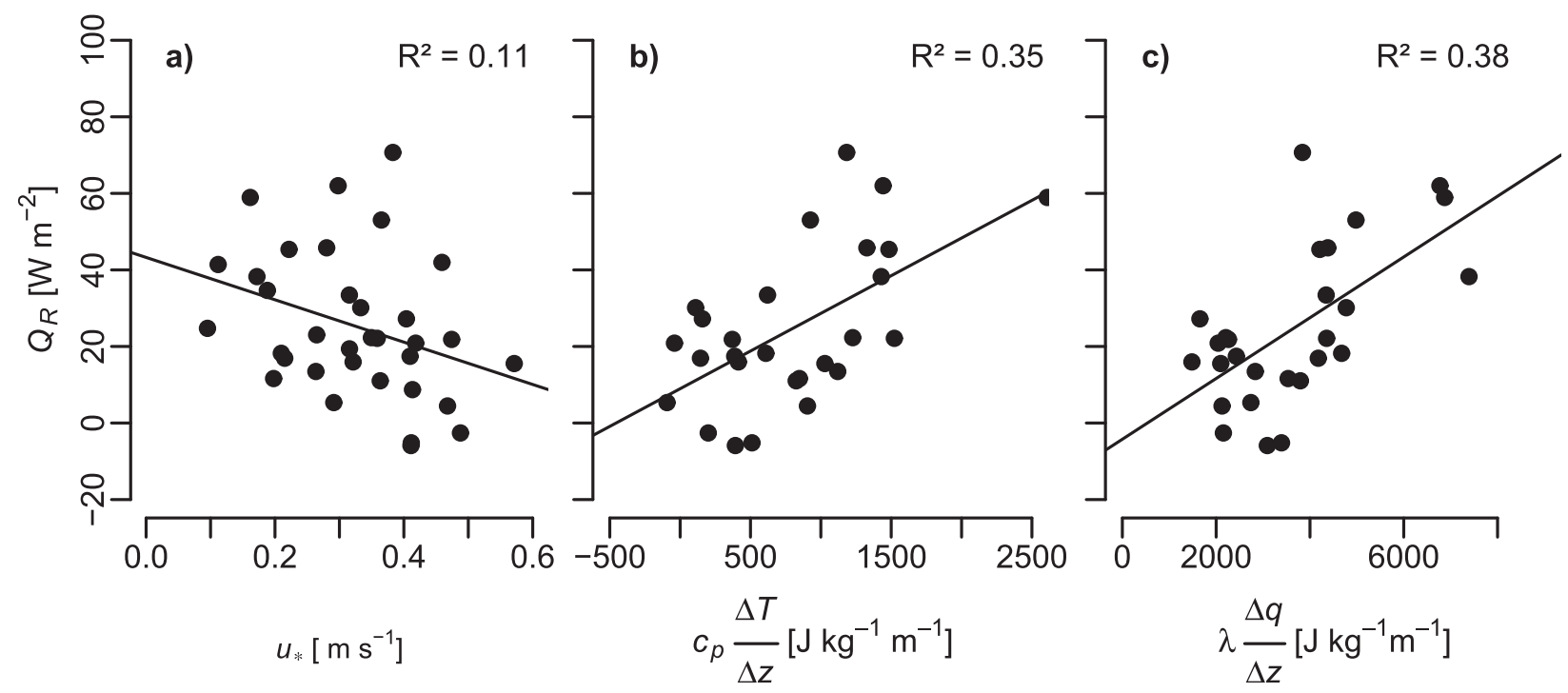

FIG. 10. Linear regression analysis between the daily averages of the energy balance residual $Q_{R}$ at Merzenhausen and (a) the friction velocity $u_{*}$, (b) the vertical gradient of temperature $\Delta T / \Delta z$ multiplied by $c_{p}$, and (c) the specific humidity $\Delta q / \Delta z$ multiplied by $\lambda$, determined from the universal functions $(0-2 \mathrm{~m})$. Days with a mean wind direction from $0^{\circ}$ to $135^{\circ}$ and less than $50 \%$ data availability were excluded from the analysis. Only the daytime data measured between 0800 and 1700 UTC were used. 
captured by the EC measurement (Fig. 5b). For this reason, the energy balance residual is negatively correlated with the friction velocity (Fig. 8a). This dependence is well known and suggests that a high intensity of mechanically induced turbulence improves the energy balance closure (Blanken et al. 1997; Wilson et al. 2002; Barr et al. 2006; Hendricks-Franssen et al. 2010; Stoy et al. 2013; Anderson and Wang 2014).

The RHI scans that were performed with the Streamline lidar on 17 and 28 April confirm that the TOS can reach almost down to the surface, since we still found strong convergence in the horizontal wind at $15 \mathrm{~m}$ AGL (Figs. 6b,c). The dual-Doppler data and the data from the Streamline lidar also suggest that TOS only affect the $u$ component in the surface layer and the $w$ component in the outer layer, which is confirmed by the wavelet spectra (Fig. 7). For this reason, TOS do not contribute much to the cospectra of $w$ and $T$ and $w$ and $q$ in the surface layer. This is the concept of the ogive test (Desjardins et al.1989), which was suggested to quantify low-frequency losses of EC data (Foken et al. 1995, 2012; Charuchittipan et al. 2014). The ogive is the cumulative integral of the cospectrum starting with the highest frequencies and calculating up to a wavelength of several hours. We applied this test using the wavelet cross spectra [Eq. (12)], but it did not indicate any significant low-frequency vertical flux contribution on 7 April (data not shown), presumably because the $w$ component was not affected and the structures were not moving with the mean wind. Our data suggest that the "missing" energy is represented rather in the horizontal fluxes.

Because the TOS affect the horizontal wind component in the surface layer, we tested whether the nonclosure of the energy balance can be related to the low-frequency part of the $u$ spectrum, but this approach was not successful because of the extreme nonstationarity of this time series. For doing spectral analysis on time series data, we need stationary conditions over many hours, a condition that was not fulfilled in the field because of the diurnal cycle, veering wind directions, and variable weather conditions. Therefore, we conclude that using point measurements alone is not sufficient to quantify the contribution of low-frequency motions to the surface energy fluxes, in particular if secondary circulations are not carried along with the mean wind. We did demonstrate that ground-based remote sensing instruments can help to detect large-scale TOS that are difficult to capture with meteorological towers.

The Doppler lidar data alone do not allow one to discern whether the observed TOS contribute to the near-surface exchange, that is, whether they are "active" turbulent motions (Townsend 1976). If we take into account the vertical gradients of temperature and moisture in the ABL, however, we can evaluate indirectly whether the TOS affect the vertical exchange of energy. At both sites, Selhausen and Merzenhausen, we found a correlation between the mean daytime energy balance residual and the moisture gradient, but a correlation was found with the gradient of potential temperature only at Merzenhausen (Figs. 8b,c, 9, and 10b,c). At Selhausen, the energy balance residual was larger when the differences in specific humidity between the surface layer and the outer layer were larger. In accord with this, the TOS may have contributed more to the latent heat flux than to the sensible heat flux at Selhausen. In other words, for adjusting the energy balance closure, a larger fraction of the residual energy should be assigned to the latent heat flux. This contradicts the cospectral similarity approach (Blanken et al. 1997; Twine et al. 2000), which says that $Q_{R}$ should be distributed among $Q_{H}$ and $Q_{E}$ according to the measured Bowen ratio. Data from aircraft measurements over the boreal forest in Canada (Eder et al. 2014) and lysimeter measurements in the Alpine region (Wohlfahrt et al. 2010) also suggest that a majority of the energy balance residual should be added to the latent heat flux. The results from the Merzenhausen site (Figs. 10b, c), however, suggest that the TOS may contribute similarly to the fluxes of sensible heat and latent heat, which supports the approach to close the energy balance by conserving the Bowen ratio (Blanken et al. 1997; Twine et al. 2000). Therefore, we cannot give a definite recommendation on how to correct the unclosed energy balance, but the partitioning of the mesoscale flux seems to be highly dependent on the measurement site.

For calculating the vertical gradients, we recommend the use of profile measurements of $\theta$ and $q$ (Fig. 8). If the profiles are not available, as was the case for the Merzenhausen site, the application of profile equations seems to be a good alternative (Figs. 9 and 10). Because these gradients are derived from biased EC fluxes estimates, however, we tested whether the magnitude of the EC fluxes alone is sufficient to explain the energy balance residual (data not shown). If so, a systematic instrumental bias could also be a major cause of the unclosed energy balance, but the correlations were much weaker $\left(R^{2}<0.18\right)$ than those in Figs. 9 and 10 . This gives us confidence that calculating the vertical gradients of $T$ and $q$ is a convenient approach for showing that the EC method does not capture the flux contributions of TOS.

In addition, we have shown that some part of the nonclosure of the energy balance can be explained by flowdistortion effects (section 3a). The 30-min averages of the vertical wind component show a strong dependence on 
wind direction for the northeastern wind sector (Figs. 3e,f). The EC systems were arranged in such a way that there is no flow distortion for the main wind direction. That is, the sonic anemometer is facing to the southwest, and the tower mountings and the measurement devices are located in the northeastern wind sector, where they deflect the wind field. This may result in a decorrelation of the vertical wind and the scalars, that is, in lower flux estimates. We accordingly calculated a lower energy balance ratio for the northeastern and eastern wind sectors at both EC towers (Figs. 3a,b). It is important to note that the automated $\mathrm{QA} / \mathrm{QC}$ routine that was applied to the data did not detect this effect, because the measured mean vertical wind component lay below the preset threshold of $0.1 \mathrm{~m} \mathrm{~s}^{-1}$ and the measured integral turbulence characteristics deviated by less than $30 \%$ from the modeled ones (Mauder and Foken 2011). Therefore, an influence of anemometer backwind deficiencies, tower mountings, and nearby instruments on the EC fluxes has to be taken into consideration for the northeastern sector, even after filtering out unreliable data using the QA/QC routine. We strongly recommend checking the processed data, especially $\bar{w}$ and $u / u_{*}$, for such effects. Because it is not clear whether the design of the anemometer or the instrumental setup is the main source of disturbance, future research on this topic would be desirable.

In summary, we showed that a large fraction of the observed variability in the energy balance residual can be explained by the friction velocity and the vertical gradients of temperature and moisture (section $3 \mathrm{c}$ ), after excluding data from wind sectors that are affected by flow distortion and after excluding measurement days with insufficient data availability. Therefore, Eqs. (14) and (15) might serve as a first step to develop a parameterization for the energy balance residual. The remaining variability results most likely from 1) the neglect of energy storage terms, which were relevant during the first days of the investigation period (i.e., at the beginning of April 2013), and 2) the random measurement error that is due to the stochastic nature of turbulence, instrumental noise, and the changing footprint of the measurement (Mauder et al. 2013).

\section{Conclusions}

We proved with field measurements that TOS with time scales of larger than 30 min can extend deep into the surface layer, and we have confirmed the dependence of the energy balance closure on friction velocity. The latter result suggests that the closure improves with enhanced mechanical mixing and increased propagation speed of the coherent structures. The vertical humidity gradient in the lower ABL also helped to explain the observed variability of $Q_{R}$, whereas the vertical temperature gradient was only relevant for one of the two sites under investigation. This finding indicates that the energy balance at the EC towers lacks closure because TOS affect the near-surface exchange. Besides TOS, there are also heterogeneity-induced mesoscale secondary circulations that are fixed in space (Lee and Black 1993; Mahrt 1998; Foken 2008b), which cannot be captured by point measurements alone. Although we did not detect them with the dual-Doppler lidar in this study area, we expect them to play a significant role in ecosystem-atmosphere exchange in complex terrain-for example, sites in mountainous areas (Brötz et al. 2014), sites close to land-water boundaries (Higgins et al. 2013), or roughness heterogeneities such as forest edges (Eder et al. 2013).

Our study also shows that point measurements are not an adequate tool for quantifying the flux contribution of TOS, because these features are three-dimensional. Ground-based remote sensing measurements give more insight into the spatial structure of the surface layer, and we were able to visualize TOS in the surface layer, but their flux contributions can only be calculated if we also know the temperature and moisture field with a high temporal and spatial resolution. Because these requirements cannot be fulfilled with current field experiments, only intensive modeling studies can help. An LES model allows for conducting virtual measurements under well-defined environmental conditions, but the investigation of near-surface exchange requires a very fine grid resolution to prevent wall effects and to resolve atmospheric turbulence instead of parameterizing it in the surface layer.

Acknowledgments. The authors thank the KITcube team-in particular, Andreas Wieser and Bianca Adler-for their assistance with the lidar and HATPRO measurements. We acknowledge field support by Alexander Graf, Martina Klein, and Daniel Dolfus of the Transregional collaborative research center (SFB/TR) 32 "Patterns in Soil-Vegetation-Atmosphere Systems: Monitoring, Modelling, and Data Assimilation" funded by the Deutsche Forschungsgesellschaft (DFG). We thank Baltasar Trancón y Widemann for providing the wavelet routine. The data acquisition for this study was conducted in the framework of the "High definition clouds and precipitation for advancing climate prediction" $\left(\mathrm{HDCP}^{2}\right)$ research initiative, funded by the German Federal Ministry of Education and Research (BMBF). A large part of this work was conducted within the Helmholtz Young Investigator Group "Capturing all relevant scales of biosphere-atmosphere exchangethe enigmatic energy balance closure problem," which 
is funded by the Helmholtz-Association through the President's Initiative and Networking Fund and by KIT.

\section{REFERENCES}

Ahlers, G., S. Grossmann, and D. Lohse, 2009: Heat transfer and large scale dynamics in turbulent Rayleigh-Bénard convection. Rev. Mod. Phys., 81, 503-537, doi:10.1103/RevModPhys.81.503.

Anderson, R. G., and D. Wang, 2014: Energy budget closure observed in paired eddy covariance towers with increased and continuous daily turbulence. Agric. For. Meteor., 184, 204-209, doi:10.1016/j.agrformet.2013.09.012.

Aubinet, M., and Coauthors, 2010: Direct advection measurements do not help to solve the night-time $\mathrm{CO}_{2}$ closure problem: Evidence from three different forests. Agric. For. Meteor., 150, 655-664, doi:10.1016/j.agrformet.2010.01.016.

Baldocchi, D., and Coauthors, 2001: FLUXNET: A new tool to study the temporal and spatial variability of ecosystem-scale carbon dioxide, water vapor, and energy flux densities. Bull. Amer. Meteor. Soc., 82, 2415-2434, doi:10.1175/1520-0477(2001)082<2415: FANTTS $>2.3 . \mathrm{CO} ; 2$.

Barr, A. G., K. Morgenstern, T. A. Black, J. H. McCaughey, and Z. Nesic, 2006: Surface energy balance closure by the eddycovariance method above three boreal forest stands and implications for the measurement of the $\mathrm{CO}_{2}$ flux. Agric. For. Meteor., 140, 322-337, doi:10.1016/j.agrformet.2006.08.007.

Blanken, P. D., and Coauthors, 1997: Energy balance and canopy conductance of a boreal aspen forest: Partitioning overstory and understory components. J. Geophys. Res., 102, 2891528 927, doi:10.1029/97JD00193.

Brötz, B., R. Eigenmann, A. Dörnbrack, T. Foken, and V. Wirth, 2014: Early-morning flow transition in a valley in lowmountain terrain under clear-sky conditions. Bound.-Layer Meteor., 152, 45-63, doi:10.1007/s10546-014-9921-7.

Businger, J. A., J. C. Wyngaard, Y. Izumi, and E. F. Bradley, 1971: Flux-profile relationships in the atmospheric surface layer. J. Atmos. Sci., 28, 181-189, doi:10.1175/1520-0469(1971)028<0181: FPRITA $>2.0 . \mathrm{CO} ; 2$.

Cantwell, B. J., 1981: Organized motion in turbulent flow. Annu. Rev. Fluid Mech., 13, 457-515, doi:10.1146/annurev.fl.13.010181.002325.

Charuchittipan, D., W. Babel, M. Mauder, J. P. Leps, and T. Foken, 2014: Extension of the averaging time in eddy-covariance measurements and its effect on the energy balance closure. Bound.-Layer Meteor., 152, 303-327, doi:10.1007/s10546-014-9922-6.

Culf, A. D., T. Foken, and J. H. C. Gash, 2004: The energy balance closure problem. Vegetation, Water, Humans and the Climate: A New Perspective on an Interactive System, P. Kabat et al., Eds., Springer, 159-166.

Desjardins, R. L., 1985: Carbon dioxide budget of maize. Agric. For. Meteor., 36, 29-41, doi:10.1016/0168-1923(85)90063-2.

_ J. I. MacPherson, P. H. Schuepp, and F. Karanja, 1989: An evaluation of aircraft flux measurements of $\mathrm{CO}_{2}$, water vapor and sensible heat. Bound.-Layer Meteor., 47, 55-69, doi:10.1007/ BF00122322.

Eder, F., A. Serafimovich, and T. Foken, 2013: Coherent structures at a forest edge: Properties, coupling and impact of secondary circulations. Bound.-Layer Meteor., 148, 285-308, doi:10.1007/ s10546-013-9815-0.

, F. De Roo, K. Kohnert, R. Desjardins, H. P. Schmid, and M. Mauder, 2014: Evaluation of two energy balance closure parametrizations. Bound.-Layer Meteor., 151, 195-219, doi:10.1007/ s10546-013-9904-0.
Emmel, C., E. Paul-Limoges, T. A. Black, and A. Christen, 2013: Vertical distribution of radiation and energy balance partitioning within and above a lodgepole pine stand recovering from a recent insect attack. Bound.-Layer Meteor., 149, 133163, doi:10.1007/s10546-013-9844-8.

Etling, D., and R. A. Brown, 1993: Roll vortices in the planetary boundary layer: A review. Bound.-Layer Meteor., 65, 215-248, doi:10.1007/BF00705527.

Finnigan, J. J., R. Clement, Y. Malhi, R. Leuning, and H. A. Cleugh, 2003: A re-evaluation of long-term flux measurement techniques. Part I: Averaging and coordinate rotation. Bound.-Layer Meteor., 107, 1-48, doi:10.1023/A:1021554900225.

Foken, T., 2008a: Micrometeorology. Springer, 308 pp.

- 2008b: The energy balance closure problem: An overview. Ecol. Appl., 18, 1351-1367, doi:10.1890/06-0922.1.

_- R. Rlugi, and G. Kramm, 1995: On the determination of dry deposition and emission of gaseous compounds at the biosphere-atmosphere interface. Meteor. Z., 4, 91-118.

—_, M. Aubinet, J. J. Finnigan, M. Y. Leclerc, M. Mauder, and K. T. Paw U, 2011: Results of a panel discussion about the energy balance closure correction for trace gases. Bull. Amer. Meteor. Soc., 92, ES13-ES18, doi:10.1175/ 2011BAMS3130.1.

- R. Leuning, S. R. Oncley, M. Mauder, and M. Aubinet, 2012: Corrections and data quality control. Eddy Covariance: A Practical Guide to Measurement and Data Analysis, M. Aubinet, T. Vesala, and D. Papale, Eds., Springer, 85-131.

Frank, J. M., W. J. Massman, and B. E. Ewers, 2013: Underestimates of sensible heat flux due to vertical velocity measurement errors in non-orthogonal sonic anemometers. Agric. For. Meteor., 171-172, 72-81, doi:10.1016/j.agrformet.2012.11.005.

Frehlich, R., 2001: Estimation of velocity error for Doppler lidar measurements. J. Atmos. Oceanic Technol., 18, 1628-1639, doi:10.1175/1520-0426(2001)018<1628:EOVEFD>2.0.CO;2.

Göckede, M., and Coauthors, 2008: Quality control of CarboEurope flux data-Part 1: Coupling footprint analyses with flux data quality assessment to evaluate sites in forest ecosystems. Biogeosciences, 5, 433-450, doi:10.5194/bg-5-433-2008.

Goulden, M. L., J. W. Munger, S. M. Fan, B. C. Daube, and S. C. Wofsy, 1996: Measurements of carbon sequestration by longterm eddy covariance: Methods and a critical evaluation of accuracy. Global Change Biol., 2, 169-182, doi:10.1111/ j.1365-2486.1996.tb00070.x.

Graf, A., and Coauthors, 2010: Boundedness of turbulent temperature probability distributions, and their relation to the vertical profile in the convective boundary layer. Bound.-Layer Meteor., 134, 459-486, doi:10.1007/s10546-009-9444-9.

Hendricks-Franssen, H. J., R. Stöckli, I. Lehner, E. Rotenberg, and S. I. Seneviratne, 2010: Energy balance closure of eddycovariance data: A multisite analysis for European FLUXNET stations. Agric. For. Meteor., 150, 1553-1567, doi:10.1016/ j.agrformet.2010.08.005.

Heusinkveld, B. G., A. F. G. Jacobs, A. A. M. Holtslag, and S. M. Berkowicz, 2004: Surface energy balance closure in an arid region: Role of soil heat flux. Agric. For. Meteor., 122, 21-37, doi:10.1016/j.agrformet.2003.09.005.

Higgins, C. W., E. Pardyiak, M. Froidevaux, V. Simeonov, and M. B. Parlange, 2013: Measured and estimated water vapor advection in the atmospheric surface layer. J. Hydrometeor., 14, 1966-1972, doi:10.1175/JHM-D-12-0166.1.

Högström, U., 1988: Non-dimensional wind and temperature profiles in the atmospheric surface layer: A re-evaluation. Bound.-Layer Meteor., 42, 55-78, doi:10.1007/BF00119875. 
_- , and A. S. Smedman, 2004: Accuracy of sonic anemometers: Laminar wind-tunnel calibrations compared to atmospheric in situ calibrations against a reference instrument. Bound.-Layer Meteor., 111, 33-54, doi:10.1023/ B:BOUN.0000011000.05248.47.

Huang, J., X. Lee, and E. Patton, 2008: A modelling study of flux imbalance and the influence of entrainment in the convective boundary layer. Bound.-Layer Meteor., 127, 273-292, doi:10.1007/ s10546-007-9254-x.

Hudgins, L. E., M. E. Mayer, and C. A. Friehe, 1993: Fourier and wavelet analysis of atmospheric turbulence. Progress in Wavelet Analysis and Applications, E. Meyers and S. Roques, Eds., Editions Frontiers, 491-498.

Inagaki, A., M. O. Letzel, S. Raasch, and M. Kanda, 2006: Impact of surface heterogeneity on energy imbalance: A study using LES. J. Meteor. Soc. Japan, 84, 187-198, doi:10.2151/jmsj.84.187.

Kanda, M., A. Inagaki, M. O. Letzel, S. Raasch, and T. Watanabe, 2004: LES study of the energy imbalance problem with eddy covariance fluxes. Bound.-Layer Meteor., 110, 381-404, doi:10.1023/ B:BOUN.0000007225.45548.7a.

Kilinc, M., J. Beringer, L. B. Hutley, V. Haverd, and N. Tapper, 2012: An analysis of the surface energy budget above the world's tallest angiosperm forest. Agric. For. Meteor., 166-167, 23-31, doi:10.1016/j.agrformet.2012.05.014

Kochendorfer, J., T. P. Meyers, J. Frank, W. J. Massman, and M. W. Heuer, 2012: How well can we measure the vertical wind speed? Implications for fluxes of energy and mass. Bound.-Layer Meteor., 145, 383-398, doi:10.1007/s10546-012-9738-1.

Kohsiek, W., C. Liebethal, T. Foken, R. Vogt, S. P. Oncley, Ch. Bernhofer, and H. A. R. Debruin, 2007: The Energy Balance Experiment EBEX-2000. Part III: Behaviour and quality of the radiation measurements. Bound.-Layer Meteor., 123, 55-75, doi:10.1007/s10546-006-9135-8.

Laubach, J., M. Raschendorfer, H. Kreilein, and G. Gravenhorst, 1994: Determination of heat and water vapour fluxes above a spruce forest by eddy correlation. Agric. For. Meteor., 71, 373-401, doi:10.1016/0168-1923(94)90021-3.

Lee, X., and T. A. Black, 1993: Atmospheric turbulence within and above a Douglas-fir stand. Part II: Eddy fluxes of sensible heat and water vapour. Bound.-Layer Meteor., 64, 369-389, doi:10.1007/ BF00711706.

Lenschow, D. H., and L. Kristensen, 1985: Uncorrelated noise in turbulence measurements. J. Atmos. Oceanic Technol., 2, 68 81, doi:10.1175/1520-0426(1985)002<0068:UNITM >2.0.CO;2.

Leuning, R., E. van Gorsel, W. J. Massman, and P. R. Isaac, 2012: Reflections on the surface energy imbalance problem. Agric. For. Meteor., 156, 65-74, doi:10.1016/ j.agrformet.2011.12.002.

Liebethal, C., B. Huwe, and T. Foken, 2005: Sensitivity analysis for two ground heat flux calculation approaches. Agric. For. Meteor., 132, 253-262, doi:10.1016/j.agrformet.2005.08.001.

Lindroth, A., M. Mölder, and F. Lagergren, 2010: Heat storage in forest biomass improves energy balance closure. Biogeosciences, 7, 301-313, doi:10.5194/bg-7-301-2010.

Löhnert, U., and O. Maier, 2012: Operational profiling of temperature using ground-based microwave radiometry at Payerne: Prospects and challenges. Atmos. Meas. Tech., 5, 1121-1134, doi:10.5194/amt-5-1121-2012.

_ _ D. D. Turner, and S. Crewell, 2009: Ground-based temperature and humidity profiling using spectral infrared and microwave observations. Part I: Simulated retrieval performance in clear-sky conditions. J. Appl. Meteor. Climatol., 48, 10171032, doi:10.1175/2008JAMC2060.1.
Mahrt, L., 1998: Flux sampling errors for aircraft and towers. J. Atmos. Oceanic Technol., 15, 416-429, doi:10.1175/ 1520-0426(1998)015<0416:FSEFAA > 2.0.CO;2.

Maronga, B., and S. Raasch, 2013: Large-eddy simulations of surface heterogeneity effects on the convective boundary layer during the LITFASS-2003 experiment. Bound.-Layer Meteor., 146, 17-44, doi:10.1007/s10546-012-9748-z.

Mauder, M., 2013: A comment on "How well can we measure the vertical wind speed? Implications for fluxes of energy and mass" by Kochendorfer et al. Bound.-Layer Meteor., 147, 329335, doi:10.1007/s10546-012-9794-6.

- and T. Foken, 2006: Impact of post-field data processing on eddy covariance flux estimates and energy balance closure. Meteor. Z., 15, 597-609, doi:10.1127/0941-2948/2006/0167.

, and _ 2011: Documentation and instruction manual of the eddy-covariance software package TK3. University of Bayreuth Dept. of Micrometeorology Rep. 46, 60 pp.

, R. L. Desjardins, and I. MacPherson, 2007: Scale analysis of airborne flux measurements over heterogeneous terrain in a boreal ecosystem. J. Geophys. Res., 112, D13112, doi:10.1029/ 2006JD008133.

, M. Cuntz, C. Drüe, A. Graf, C. Rebmann, H. P. Schmid, M. Schmidt, and R. Steinbrecher, 2013: A strategy for quality and uncertainty assessment of long-term eddy-covariance measurements. Agric. For. Meteor., 169,122-135, doi:10.1016/ j.agrformet.2012.09.006.

Meyers, T. P., and S. E. Hollinger, 2004: An assessment of storage terms in the surface energy balance of maize and soybean. Agric. For. Meteor., 125, 105-115, doi:10.1016/j.agrformet.2004.03.001.

Moeng, C. H., and P. P. Sullivan, 1994: A comparison of shear- and buoyancy-driven planetary boundary layer flows. J. Atmos. Sci., 51, 999-1022, doi:10.1175/1520-0469(1994)051<0999: $\mathrm{ACOSAB}>2.0 . \mathrm{CO} ; 2$.

Moore, C. J., 1986: Frequency response corrections for eddy correlation systems. Bound.-Layer Meteor., 37, 17-35, doi:10.1007/ BF00122754.

Nakai, T., and K. Shimoyama, 2012: Ultrasonic anemometer angle of attack errors under turbulent conditions. Agric. For. Meteor., 162-163, 14-26, doi:10.1016/j.agrformet.2012.04.004.

- M. K. Van der Molen, J. H. C. Gash, and Y. Kodama, 2006: Correction of sonic anemometer angle of attack errors. Agric. For. Meteor., 136, 19-30, doi:10.1016/j.agrformet.2006.01.006.

Newsom, R. K., R. Calhoun, D. Ligon, and J. Allwine, 2008: Linearly organized turbulence structures observed over a suburban area by dual-Doppler lidar. Bound.-Layer Meteor., 127, 111-130, doi:10.1007/s10546-007-9243-0.

Oncley, S., and Coauthors, 2007: The Energy Balance Experiment EBEX-2000. Part I: Overview and energy balance. Bound.Layer Meteor., 123, 1-28, doi:10.1007/s10546-007-9161-1.

Panin, G. N., and Ch. Bernhofer, 2008: Parametrization of turbulent fluxes over inhomogeneous landscapes. Izv. Atmos. Ocean. Phys., 44, 701-716, doi:10.1134/S0001433808060030.

_, G. Tetzlaff, and A. Raabe, 1998: Inhomogeneity of the land surface and problems in the parameterization of surface fluxes in natural conditions. Theor. Appl. Climatol., 60, 163-178, doi:10.1007/s007040050041.

Robinson, S. K., 1991: Coherent motions in the turbulent boundary layer. Annu. Rev. Fluid Mech., 23, 601-639, doi:10.1146/ annurev.fl.23.010191.003125.

Rose, T., S. Crewell, U. Löhnert, and C. Simmer, 2005: A network suitable microwave radiometer for operational monitoring of the cloudy atmosphere. Atmos. Res., 75, 183-200, doi:10.1016/ j.atmosres.2004.12.005. 
Sakai, R. K., D. R. Fitzjarrald, and K. E. Moore, 2001: Importance of low-frequency contributions to eddy fluxes observed over rough surfaces. J. Appl. Meteor., 40, 2178-2192, doi:10.1175/ 1520-0450(2001)040<2178:IOLFCT >2.0.CO;2.

Schmid, H. P., 1997: Experimental design for flux measurements: Matching scales of observations and fluxes. Agric. For. Meteor., 87, 179-200, doi:10.1016/S0168-1923(97)00011-7.

, C. S. B. Grimmond, F. Cropley, B. Offerle, and H. B. Su, 2000: Measurements of $\mathrm{CO}_{2}$ and energy fluxes over a mixed hardwood forest in the mid-western United States. Agric. For. Meteor., 103, 357-374, doi:10.1016/S0168-1923(00)00140-4.

Schmidt, H., and U. Schumann, 1989: Coherent structure of the convective boundary layer derived from large-eddy simulations. J. Fluid Mech., 200, 511-562, doi:10.1017/ S0022112089000753.

Schmidt, M., T. G. Reichenau, P. Fiener, and K. Schneider, 2012: The carbon budget of a winter wheat field: An eddy covariance analysis of seasonal and inter-annual variability. Agric. For. Meteor., 165, 114-126, doi:10.1016/j.agrformet.2012.05.012.

Schotanus, P., F. T. M. Nieuwstadt, and H. A. R. de Bruin, 1983: Temperature measurement with a sonic anemometer and its application to heat and moisture fluxes. Bound.-Layer Meteor., 26, 81-93, doi:10.1007/BF00164332.

Staebler, R. M., and D. R. Fitzjarrald, 2004: Observing subcanopy $\mathrm{CO}_{2}$ advection. Agric. For. Meteor., 122, 139-156, doi:10.1016/ j.agrformet.2003.09.011.

Stawiarski, C., 2014: Optimizing dual-Doppler lidar measurements of surface layer coherent structures with large-eddy simulations. Ph.D. thesis, Karlsruhe Institute of Technology, 197 pp. [Available online at http://digbib.ubka.uni-karlsruhe.de/ volltexte/1000039726.]

_, K. Träumner, C. Knigge, and R. Calhoun, 2013: Scopes and challenges of dual-Doppler lidar wind measurements-An error analysis. J. Atmos. Oceanic Technol., 30, 2044-2062, doi:10.1175/JTECH-D-12-00244.1.

Steinfeld, G., M. Letzel, S. Raasch, M. Kanda, and A. Inagaki, 2007: Spatial representativeness of single tower measurements and the imbalance problem with eddy-covariance fluxes: Results of a large-eddy simulation study. Bound.-Layer Meteor., 123, 77-98, doi:10.1007/s10546-006-9133-x.
Stoy, P. C., and Coauthors, 2013: A data-driven analysis of energy balance closure across FLUXNET research sites: The role of landscape scale heterogeneity. Agric. For. Meteor., 171-172, 137-152, doi:10.1016/j.agrformet.2012.11.004.

Swinbank, W. C., 1951: The measurement of vertical transfer of heat and water vapor by eddies in the lower atmosphere. J. Meteor., 8, 135-145, doi:10.1175/1520-0469(1951)008<0135: TMOVTO $>2.0 . \mathrm{CO} ; 2$.

Torrence, C., and G. P. Compo, 1998: A practical guide to wavelet analysis. Bull. Amer. Meteor. Soc., 79, 61-78, doi:10.1175/ 1520-0477(1998)079<0061:APGTWA > 2.0.CO;2.

Townsend, A. A., 1976: The Structure of Turbulent Shear Flow. Cambridge University Press, 429 pp.

Träumner, K., T. Damian, C. Stawiarski, and A. Wieser, 2014: Turbulent structures and coherence in the atmospheric surface layer. Bound.-Layer Meteor., doi:10.1007/s10546-014-9967-6, in press.

Twine, T. E., and Coauthors, 2000: Correcting eddy-covariance flux underestimates over a grassland. Agric. For. Meteor., 103, 279300, doi:10.1016/S0168-1923(00)00123-4.

Webb, E. K., G. I. Pearman, and R. Leuning, 1980: Correction of flux measurements for density effects due to heat and water vapour transfer. Quart. J. Roy. Meteor. Soc., 106, 85-100, doi:10.1002/qj.49710644707.

Wiernga, J., 1993: Representative roughness parameters for homogeneous terrain. Bound.-Layer Meteor., 63, 323-363, doi:10.1007/BF00705357.

Wilczak, J., S. Oncley, and S. Stage, 2001: Sonic anemometer tilt correction algorithms. Bound.-Layer Meteor., 99, 127-150, doi:10.1023/A:1018966204465.

Wilson, K., and Coauthors, 2002: Energy balance closure at FLUXNET sites. Agric. For. Meteor., 113, 223-243, doi:10.1016/ S0168-1923(02)00109-0.

Wohlfahrt, G., C. Irschick, B. Thalinger, L. Hörtnagl, N. Obojes, and A. Hammerle, 2010: Insights from independent evapotranspiration estimates for closing the energy balance: A grassland study. Vadose Zone J., 9, 1025-1033, doi:10.2136/vzj2009.0158.

Zacharias, S., and Coauthors, 2011: A network of terrestrial environmental observatories in Germany. Vadose Zone J., 10, 955 973, doi:10.2136/vzj2010.0139. 